OPEN ACCESS

Edited by:

Nicole Clemence Roy, University of Otago, New Zealand

Reviewed by:

Sergio Polakof,

Institut National de la Recherche Agronomique (INRA), France

Sophie Gallier

Dairy Goat Co-Operative

New Zealand

Thomas Thymann,

University of Copenhagen, Denmark

*Correspondence:

Isabelle Le Huërou-Luron

Isabelle.luron@inrae.fr

Specialty section:

This article was submitted to

Nutrition and Metabolism,

a section of the journal

Frontiers in Nutrition

Received: 08 October 2020 Accepted: 14 January 2021

Published: 24 February 2021

Citation:

Lemaire M, Ménard O, Cahu A, Nogret I, Briard-Bion V, Cudennec B, Cuinet I, Le Ruyet P, Baudry $C$,

Dupont D, Blat S, Deglaire A and Le Huërou-Luron I (2021) Addition of

Dairy Lipids and Probiotic Lactobacillus fermentum in Infant Formulas Modulates Proteolysis and

Lipolysis With Moderate

Consequences on Gut Physiology and Metabolism in Yucatan Piglets.

Front. Nutr. 8:615248.

doi: 10.3389/fnut.2021.615248

\section{Addition of Dairy Lipids and Probiotic Lactobacillus fermentum in Infant Formulas Modulates Proteolysis and Lipolysis With Moderate Consequences on Gut Physiology and Metabolism in Yucatan Piglets}

\author{
Marion Lemaire ${ }^{1,2}$, Olivia Ménard ${ }^{3}$, Armelle Cahu ${ }^{1}$, Isabelle Nogret ${ }^{1}$, Valérie Briard-Bion ${ }^{3}$, \\ Benoit Cudennec ${ }^{4}$, Isabelle Cuinet ${ }^{2}$, Pascale Le Ruyet ${ }^{2}$, Charlotte Baudry ${ }^{2}$, \\ Didier Dupont ${ }^{3}$, Sophie Blat ${ }^{1}$, Amélie Deglaire ${ }^{3}$ and Isabelle Le Huërou-Luron ${ }^{1 *}$ \\ ${ }^{1}$ Institut NuMeCan, INRAE, INSERM, Univ Rennes, St-Gilles, France, ${ }^{2}$ Lactalis R\&D, Retiers, France, ${ }^{3}$ STLO, INRAE, Institut \\ Agro, Rennes, France, ${ }^{4}$ UMR Transfrontalière BioEcoAgro, Univ. Lille, INRAE, Univ. Liège, UPJV, YNCREA, Univ. Artois, Univ. \\ Littoral Côte d'Opale, ICV - Institut Charles Viollette, Lille, France
}

Breast milk is the gold standard in neonatal nutrition, but most infants are fed infant formulas in which lipids are usually of plant origin. The addition of dairy lipids and/or milk fat globule membrane extracts in formulas improves their composition with beneficial consequences on protein and lipid digestion. The probiotic Lactobacillus fermentum (Lf) was reported to reduce transit time in rat pups, which may also improve digestion. This study aimed to investigate the effects of the addition of dairy lipids in formulas, with or without Lf, on protein and lipid digestion and on gut physiology and metabolism. Piglets were suckled from postnatal days 2 to 28, with formulas containing either plant lipids (PL), a half-half mixture of plant and dairy lipids (DL), or this mixture supplemented with $L f(D L+L f)$. At day 28, piglets were euthanized 90 min after their last feeding. Microstructure of digesta did not differ among formulas. Gastric proteolysis was increased $(P<0.01)$ in $\mathrm{DL}$ and $\mathrm{DL}+\mathrm{Lf}(21.9 \pm 2.1$ and $22.6 \pm 1.3 \%$, respectively) compared with $\mathrm{PL}(17.3 \pm 0.6 \%)$ and the residual proportion of gastric intact caseins decreased $(p<0.01)$ in $\mathrm{DL}+\mathrm{Lf}(5.4 \pm 2.5 \%)$ compared with $\mathrm{PL}$ and $\mathrm{DL}$ (10.6 $\pm 3.1 \%$ and $21.8 \pm 6.8 \%$, respectively). Peptide diversity in ileum and colon digesta was lower in PL compared to $\mathrm{DL}$ and $\mathrm{DL}+\mathrm{Lf}$. DL and $\mathrm{DL}+\mathrm{Lf}$ displayed an increased $(p<0.01)$ proportion of diacylglycerol/cholesterol in jejunum and ileum digesta compared to $\mathrm{PL}$ and tended $(p=0.07)$ to have lower triglyceride/total lipid ratio in ileum $\mathrm{DL}+\mathrm{Lf}(0.019 \pm 0.003)$ as compared to $\mathrm{PL}(0.045 \pm 0.011)$. The percentage of endocrine tissue and the number of islets in the pancreas were decreased $p$ $<0.05)$ in $\mathrm{DL}+\mathrm{Lf}$ compared with $\mathrm{DL}$. DL+Lf displayed a beneficial effect on host defenses [increased goblet cell density in jejunum $(p<0.05)$ ] and a trophic effect 
[increased duodenal $(p=0.09)$ and jejunal $(p<0.05)$ weights]. Altogether, our results demonstrate that the addition of dairy lipids and probiotic Lf in infant formula modulated protein and lipid digestion, with consequences on lipid profile and with beneficial, although moderate, physiological effects.

Keywords: infant formula, milk fat, probiotic, digestion, intestinal physiology, glucagon-like peptide-1

\section{INTRODUCTION}

Early nutrition is essential to ensure optimal infant growth and development, especially regarding the digestive functions, which are immature at birth (1). While human milk is recognized as the gold standard for infant nutrition, a large proportion of them are formula-fed (2). Infant formulas have been much improved over the last decades regarding their nutritional content; however, differences remain between infant formulas and human milk regarding their non-nutritive composition, i.e., protein/lipid structure, oligosaccharide, and bacterial content (3).

At the supramolecular level, human and bovine milk fat is organized under its native form into dispersed globules enveloped in a biological membrane called milk fat globule membrane (MFGM). However, the step of homogenization during infant formula processing is conducted to uniformly distribute submicronic droplets and impact the compositional and organizational architecture of the lipid-water interface (3).

At the molecular level, the triacylglycerol structure, i.e., the regiodistribution of the fatty acids, impacts fatty acid absorption. This is of particular importance for palmitic acid, a major fatty acid in human milk. In the latter, more than $70 \%$ of the palmitic acid is located in the sn-2 position, while this is true for $<20 \%$ of the palmitic acid from palm oil, a major fat source for infant formula based on plant oil. Dairy lipids present an intermediate profile, with $40-45 \%$ of palmitic acid in this inner position $(4,5)$. Human pancreatic lipase is $\mathrm{sn}-1,3$ specific, and when palmitic acid is located at these positions, its absorption as non-esterified fatty acids is reduced as it tends to form calcium soap that is excreted in stool. On the contrary, when palmitic acid is esterified in sn-2 position, pancreatic lipolysis results in the formation of water-soluble palmitoyl-monoglycerol, which is well-absorbed. Accordingly, palmitic acid and calcium have been shown to be better absorbed in breastfed infants as compared to infants fed plant oil-based formulas (6).

A better understanding of the impact of the formula matrix effect onto its digestion in the infant gastrointestinal tract is therefore essential to optimize their formulation and improve the health of formula-fed infants. However, ethical and financial constraints of clinical studies limit knowledge. In vitro systems designed to mimic infant digestion, although relevant, cannot reproduce all the biological complexity of the digestive tract, such as digestion and absorption, hormonal feedbacks, neural interactions, host and microbe interactions, and microbe and microbe interactions. Piglet was identified as a more appropriate in vivo model to study infant digestion (7). In this model, the addition of DLs and MFGM extracts was shown to have structural and biochemical consequences on infant formula digestion, decreasing small intestinal digestion of casein and $\beta$-lactoglobulin and leading to more numerous $\beta$-casein peptides in intestinal contents, but increasing small intestinal lipid digestion (8). Besides, the administration of MFGM extracts with probiotic Lactobacillus fermentum CECT 5716 (Lf), lactic acid bacteria originally isolated from human milk (9), was shown to decrease the whole gut transit time of rat pups (10). Interestingly, this effect was not observed when MFGM extracts were provided alone, suggesting a potential role of probiotic Lf on infant formula digestion. Whether all these features remain true when DLs without additional supply of MFGM are provided alone or with the Lf probiotic in infant formulas is unknown.

It was previously demonstrated that the addition of dairy lipids to replace partially plant lipids and without additional supply of MFGM extracts and probiotic Lf in infant formula had a beneficial impact on the intestinal endocrine function later in adulthood, enhancing cecal GLP-1 content and GLP-1 meal-stimulated secretion in adult mini-pigs (11). However, the impact of infant formula containing dairy lipids with or without probiotic Lf on the piglet intestinal endocrine function and the consequences on pancreas maturation and glucose homeostasis are currently unknown. Addition of dairy lipids in the infant formula, inducing modification in proteolysis and the presence of peptides more distally in the intestine as described above, could stimulate GLP-1 secretion by the distal L-cells in ileum $(12,13)$, an effect that could be enhanced if transit time is also decreased as described above with Lf.

Our hypothesis was that the addition of dairy lipids and probiotic Lf in infant formulas could impact their digestion and consequently piglet lipid and protein metabolism. The objective of this study was to compare the digestion of infant formulas containing dairy lipids in the presence or absence of probiotic Lf to a reference formula containing only plant lipids and to evaluate their metabolic impact in infant formula-fed piglets.

\section{METHODS}

\section{Ethical Approval}

The present study was designed and conducted in compliance with the current ethical standards of the European and French guidelines (directive 2010/63/EU and decree 2013118, respectively). The ethics committees of CREEA (Rennes Committee of Ethics in Animal Experimentation) and of France's Ministry of Higher Education and Research approved the protocol (authorization \#2016011111546978). Animals were observed daily throughout the experimental protocol to ensure their welfare, and they received no medication or antibiotic treatment. 


\section{Animals and Study Design}

The study design has already been published in Lemaire et al. (11). A total of 27 female and male (11 and 16, respectively) Yucatan piglets (Saint-Gilles, France) were used in three replicates. One animal was excluded from the analyses because of health issues. Piglets were separated from their sow at postnatal day (PND) 2 and housed in individual stainless-steel metabolic cages. They were fed one of the three experimental formulas with an automatic milk feeder as previously described (14) until weaning, i.e., at PND28. To account for litter-to-litter variation, three piglets with a body weight (BW) close to the mean birth weight of the litter were selected from each litter and assigned to one of the three formulas. Allocation to formulas was balanced between groups for birth weight, BW at PND2, and sex. Formulas were rehydrated each day at $20 \%$ dry matter extract in water before distribution. The formula was allocated in 10 meals automatically distributed during the day. BW was measured twice a week, and feeding amounts were adjusted accordingly. The daily net energy offered was $1450 \mathrm{~kJ} / \mathrm{kg} \mathrm{BW} \mathrm{BW}^{0.75}$. Formula intake was automatically recorded for each meal. The average daily volume of formula intake was $220 \pm 4 \mathrm{~mL} / \mathrm{kg}(\mathrm{BW})^{0.75}$. Piglets were euthanized at PND28, and tissues were collected and weighed.

\section{Diets}

Formulas were manufactured by Lactalis (Retiers, France) and adapted to meet piglet energy and protein requirements. The three formulas had the same energy, protein, lipid, and carbohydrate levels. They differed by the lipid origin, only plant lipids $(n=9)$ vs. half-half plant lipids and dairy lipids $(n=9)$, and the supplementation with $\mathrm{Lf}(\mathrm{DL}+\mathrm{Lf}, n=8)$, as described in Table 1. Dairy lipids came from the cream, which may contain some residual MFGM that may account for $2-6 \%$ of the fat mass (15), but there was no addition of specific MFGM. The experimental formulas contained higher amounts of protein and lipid and a lower amount of lactose than a standard human infant formula in order to meet the piglet requirement. Lipid:protein and linoleic acid: $\alpha$-linolenic acid $(\omega 6: \omega 3=6-7)$ ratios were kept similar to those found in commercial infant formulas. The formulas were based on a mixture of skim milk and whey protein concentrate powders to reach a casein:whey proteins ratio of 30:70 wt/wt.

\section{Postmortem Sampling}

According to our previous study on the kinetics of protein digestion, the 90-min postprandial sampling time is the optimal timepoint considering the progress of the digestion process and the appearance of dietary peptides in all digestive compartments from stomach to the ileum (16). Therefore, piglets were euthanized $90 \mathrm{~min}$ postprandially in the experimental slaughterhouse by electrical stunning immediately followed by exsanguination.

Blood was collected in tubes containing $\mathrm{K}^{2}$-EDTA for glucose, insulin, haptoglobin, and lipid profiles and in tubes containing $\mathrm{K}^{2}$-EDTA plus an anti-dipeptidyl peptidase-IV (DPP-IV, 10 $\mu \mathrm{L} / \mathrm{mL}$ of blood) for GLP-1 (Millipore, Billerica, MA, USA). After centrifugation $\left(10 \mathrm{~min}, 2,500 \mathrm{~g}, 4^{\circ} \mathrm{C}\right)$, plasma samples for
TABLE 1 | Composition of infant formulas.

\begin{tabular}{lccc}
\hline g/100 g of powder & PL $^{\mathbf{a}}$ & DL $^{\mathbf{a}}$ & DL+Lf $^{\mathbf{a}}$ \\
\hline Proteins & 17.8 & 17.9 & 17.9 \\
Lipids & 43.6 & 44.7 & 44.6 \\
Carbohydrates & 33.1 & 32.3 & 32.2 \\
Minerals & 3.5 & 3.4 & 3.4 \\
Energy (kJ) & 2476 & 2506 & 2501 \\
Lactobacillus fermentum CECT 5716 (Lf) $^{\text {Phospholipids }}{ }^{b}$ & - & - & $1.9 \mathrm{E}+08$ \\
Cholesterol $^{c}$ & 0.40 & 2.52 & 2.52 \\
\hline
\end{tabular}

${ }^{a}$ Formulas contained as lipids either only plant lipids (PL), a half-half mixture of plant and dairy lipids $(D L)$, or a half-half mixture of plant and dairy lipids supplemented with $L f$ $(D L+L f)$. Formulas were rehydrated at $20 \%$ of dry extract. Lipid sources of the $P L$ formula were palm oil (71.7\%), rapeseed oil (23.2\%), and refined sunflower oil (5.1\%); those of the $D L$ and $D L+L f$ formulas were cream (53.4\%), rapeseed oil (21.1\%), refined sunflower oil (13.1\%), and high oleic sunflower oil (12.4\%).

${ }^{b}$ Concentrations of phospholipids hereby indicated were values obtained in a previous production batch of similar infant formulas.

${ }^{c}$ Calculated concentrations of cholesterol were based on the cholesterol content of ingredients used in PL and D $L( \pm L f)$ formulas.

glucose, insulin, haptoglobin, and lipid assays were stored at $-20^{\circ} \mathrm{C}$ and the ones for GLP- 1 assay at $-80^{\circ} \mathrm{C}$. Brain, liver, pancreas, perirenal, and subcutaneous adipose tissues were weighed. Duodenum, proximal and median jejunum, ileum, cecum, and colon were weighed (full and empty), and their length recorded. The digestive contents from the stomach, duodenum, proximal and median jejunum, ileum, and colon were collected by exerting a gentle pressure with the fingers.

Samples of digesta collected for in vitro intestinal secreting tumor cell line (STC-1) assays were stored at $-20^{\circ} \mathrm{C}$ until used. Protease inhibitors were added in digesta collected for protein digestion analysis: pepstatin A $(0.73 \mathrm{mM} ; 10 \mu \mathrm{L} / \mathrm{mL}$ of stomach digesta) and Pefabloc $(0.1 \mathrm{M} ; 50 \mu \mathrm{L} / \mathrm{mL}$ of small and large intestinal digesta). Before storage at $-20^{\circ} \mathrm{C}$ until further analysis, $\mathrm{pH}$ was measured. Digestive content aliquots were submitted to the direct lipid Folch extraction, as previously described (17). Briefly, $400 \mu \mathrm{L}$ of digesta sample was mixed with $2.4 \mathrm{~mL}$ of chloroform/methanol $(2: 1 \mathrm{vol} / \mathrm{vol})$ and acidified with $160 \mu \mathrm{L}$ of $\mathrm{HCl} 0.1 \mathrm{~N}$ to stop lipolysis. The extract was then rinsed with $\mathrm{NaCl} 0.73 \%(100 \mu \mathrm{L})$ and $600 \mu \mathrm{L}$ of chloroform/methanol (2:1 vol/vol). The chloroformic phase containing the lipid fraction was recovered and stored at $-20^{\circ} \mathrm{C}$ for further lipid analyses. In addition, samples of the experimental formulas and digestive contents were collected for chemical and structural characterizations.

Proximal jejunal, ileal, and cecal tissue segments were rinsed with cold phosphate-buffered saline (PBS) and fixed in $4 \%$ paraformaldehyde for $48 \mathrm{~h}$ until further dehydration in ethanol and embedding in paraffin for morphometry analysis. Adjacent pieces of cecal and colonic tissues were rinsed with cold PBS and stored at $-80^{\circ} \mathrm{C}$ until GLP-1 extraction and assay. Mucosa was scrapped from a $10-\mathrm{cm}$ ileal segment for GLP-1 assays. One- $\mathrm{cm}^{3}$ sample of pancreas was directly frozen and stored at $-80^{\circ} \mathrm{C}$ for insulin extraction and analysis, and another $\mathrm{cm}^{3}$ was fixed in $4 \%$ paraformaldehyde for immunohistochemistry. 


\section{Structural Characterization of Experimental Formulas and Digestive Contents}

\section{Particle Size Measurements}

Particle size distribution was measured on the experimental formulas by laser light scattering using a Mastersizer 2000 (Malvern Instruments, Malvern, UK), with two laser sources at 466 and $633 \mathrm{~nm}$. Refractive indexes used were 1.462 for vegetable oil and 1.333 for water (dispersion solution in the measurement cell). Samples were diluted in MilliQ-water in the measurement cell, either directly or after a 10-fold dilution in sodium dodecyl sulfate (SDS 1\%), an anionic surfactant allowing aggregate dissociation. Measurements were performed in triplicates. Mean particle size distribution was represented by distribution curve, and mode diameter (diameter of the most frequent particles), volume weighted mean diameter $(\mathrm{D}[4,3])$, and the specific surface area (SS) developed by the particles were calculated.

\section{Confocal Laser Scanning Microscopy}

The microstructures of the experimental formulas and of the digestive contents of all tissue segments of the intestine were observed as previously described in Bourlieu et al. (17). Briefly, a Nikon C1Si confocal laser scanning microscopy was used on an inverted microscope TE2000-E (Nikon, Champigny-surMarne, France) operated with an argon laser (excitation at $488 \mathrm{~nm}$ ) and two He-Ne lasers (excitations at 543 and $633 \mathrm{~nm}$ ). A $40 \times$ oil-immersion objective was used for all images, and three fluorescent dyes were used to localize apolar lipids (Lipidtox ${ }^{\circledR}$ ), proteins (Fast Green), and amphiphilic compounds (RhodamineDOPE $\left.^{\circledR}\right)$. The microstructure was assessed on the three infant formulas and on the digesta from three pigs per formula group (one per replicate).

\section{Biochemical Characterization Proteins}

SDS-polyacrylamide gel electrophoresis (PAGE) was performed on the experimental formulas and gastric contents using 4$12 \%$ polyacrylamide NuPAGE Novex bis-Tris 15-well-precast gels (Invitrogen, Carlsbad, CA, USA) and according to the manufacturer's instructions. Samples were diluted with NuPAGE ${ }^{\circledR}$ LDS sample buffer and then treated with $0.5 \mathrm{M}$ DLdithiothreitol and deionized water. The dilution of the formula by the gastric secretion was estimated based on the dry matter extract of the digesta compared to the dry matter of the formula. Twenty microliters of diluted sample containing 10 $\mu \mathrm{g}$ of protein was loaded into each well. Mark 12 Unstained Standard (Invitrogen) was used as a molecular weight ( $\mathrm{Mw})$ marker to identify the position of the bands. Gels were fixed in $40 \%$ (vol/vol) ethanol, $10 \%$ (vol/vol) acetic acid and 50\% (vol/vol) deionized water and were rinsed for $30 \mathrm{~min}$ in deionized water before overnight staining with Bio-Safe Coomassie stain (BioRad Laboratories, France). Discoloration of gels was performed with water. Image analysis of SDS-PAGE gels was carried out using Image Scanner III (GE Healthcare Europe GmbH, Velizy-Villacoublay, France), followed by densitometry of each band using the software Image Quant $\mathrm{TL}^{\mathrm{TM}}$ (GE Healthcare
Europe GmbH, Velizy-Villacoublay, France). The percentage of each intact protein present in stomach $90 \mathrm{~min}$ postprandially was thus estimated in comparison with that present in the experimental formula.

\section{$\mathrm{NH}_{2}$ Quantification}

The method was adapted from Darrouzet-Nardi et al. (18). It consisted in a spectrophotometric microplate analysis based on the reaction of orthophthaldialdehyde with primary amines in the presence of dithiothreitol resulting in 1-alkylthio-2alkylisondole detected at $340 \mathrm{~nm}$. The total content of primary amines in the experimental formulas was determined after total acid hydrolysis (6N hydrochloric acid, at $110^{\circ} \mathrm{C}$ for $24 \mathrm{~h}$ in vacuum-sealed glass tubes).

\section{Peptidomic Analysis}

Peptides in the three infant formulas and in the digestive samples (from stomach to colon, $n=99$ ) were identified and quantified semiquantitatively by tandem mass spectrometry (Q-exactive, Thermo Scientific, Sans Jose, USA), such as described in Deglaire et al. (19). A home-made database for bovine milk proteins, based on the protein sequences as reviewed in uniport.org, was used for peptide identification. Bioactive peptides were searched within the database of BIOPEP (20), and prediction of antimicrobial activity was examined using CAMPR3 (21). Peptides were considered as antimicrobial peptide (AMP) when the score reached at least 0.5 on both methods that were support vector machine and random forest classifiers, recognized as the best-performing AMP predictors (22).

\section{Lipid Analysis \\ Total Fatty Acids}

The fatty acid composition of the formulas (C8:0-C24:0) was analyzed by gas chromatography coupled to a flame ionization detector by direct transmethylation, as described in Oliveira et al. (23). Samples were injected in duplicate.

\section{Free Fatty Acids}

Gastric free fatty acids (FFAs) (C4:0 to C20:0) were analyzed on gastric digesta by gas chromatography after lipid extraction using the Folch method and followed by a solid phase extraction (24). Three internal standards $(160 \mu \mathrm{L}$ of $\mathrm{C} 5, \mathrm{C} 11$, and $\mathrm{C} 17$ at 0.5 $\mathrm{mg} / \mathrm{mL}$ ) were added to samples prior to extraction as described previously (25). Samples were injected in duplicate. The gastric lipolysis degree was determined based on the total amount of FFA related to the estimated amount of total fatty acids present in the digestive content, the latter being determined based on the formula dilution such as indicated by the dry matter extract of the digesta.

\section{Lipid Class Analysis}

Thin-layer chromatography (TLC) was conducted to follow the evolution of the different lipid classes between stomach, proximal jejunum, and ileum digestive contents at 90 min postprandially as compared to undigested formula. A digesta volume equivalent to $60 \mu \mathrm{g}$ of experimental formula lipids was spotted on silica gel plates $(10 \times 20 \mathrm{~cm}, 0.25 \mathrm{~mm}$, Si G60, Merck). An Automatic TLC Sampler III (CAMAG, Muttenz, Switzerland) was used. Plates were immersed in hexane/diethyl ether/acetic acid (70:30:2 
$\mathrm{v} \cdot \mathrm{v}^{-1} \mathrm{v}^{-1}$ ) and then stained by immersion in copper sulfate $\mathrm{II} /$ orthophosphoric acid solution and heated $\left(15 \mathrm{~min}, 150^{\circ} \mathrm{C}\right)$. Image analyses of the plates were performed as described for SDS-PAGE gels, allowing semiquantification of the different lipid classes, using the undigested formula as the reference.

\section{Morphometry and Immunohistochemical Analyses}

Seven- $\mu \mathrm{m}$ sections were stained with hematoxylin and eosin and examined under a light microscope (Nikon Eclipse E400, Nikon Instruments, France) using image analysis software (NISElements AR 3.0, Nikon Instruments) as described (26). Villus, crypt, and goblet cell numbers were measured in at least 15-20 well-oriented crypt-villus units per piglet.

Fresh cecum, colon, and pancreas were fixed in $4 \%$ paraformaldehyde for $48 \mathrm{~h}$ at room temperature. They were then placed at $4^{\circ} \mathrm{C}$ in PBS containing 30\% sucrose and embedded in the Tissue-Tek Optimum Cutting Temperature compound (Sakura Finetek Europe B. V., Zoeterwoude, the Netherlands), frozen in isopentane, and sectioned using a cryostat-microtome. Immunohistochemical analysis of cecum, colon, and pancreas was processed as previously described (11) to determine the number of enteroendocrine (chromogranin A-labeled) cells and GLP-1-secreting cells per area of mucosa, and the percentage of endocrine tissue and the number and diameter of islets in the pancreas.

\section{Glucose, Lipid, Haptoglobin, Insulin, and GLP-1 Assays}

Plasma glucose, FFA, triglycerides, total cholesterol, high-density lipoprotein cholesterol and haptoglobin were assessed by an automated spectrophotometric method (Konelab 20i, Thermo Fisher Scientific, Illkirsh, France) using specific commercial kits (Biomérieux, Bruz, France). The intra-assay coefficient of variation was $<5 \%$.

Insulin content was extracted from the pancreas by homogenization in $10 \mathrm{~mL}$ of an ethanol acid solution $(75 \%$ absolute ethanol, 23.5\% ultrapure $\mathrm{H}_{2} \mathrm{O}, 1.5 \% \mathrm{HCl} 12 \mathrm{~N}$ ) (Polytron 3100, Kinematica, 25,000 rpm, $2 \times 20 \mathrm{~s}$ ). After an overnight storage at $-20^{\circ} \mathrm{C}$, samples were centrifuged $(30 \mathrm{~min}$, $190 \mathrm{~g}, 4^{\circ} \mathrm{C}$ ), and supernatants stored at $-20^{\circ} \mathrm{C}$. Ethanol acid solution $(10 \mathrm{~mL})$ was added to pellets for a second extraction, stored overnight at $-20^{\circ} \mathrm{C}$, and centrifuged $\left(30 \mathrm{~min}, 190 \mathrm{~g}, 4^{\circ} \mathrm{C}\right)$. Supernatants were collected and pooled to the ones from the first extraction and diluted in a PBS/bovine serum albumin solution $(1: 3,000)$, and pancreas insulin concentration and plasma insulin were measured by a radioimmunoassay method, using iodinated porcine insulin as a tracer (INSULIN-CT, Cisbio International, Gif sur Yvette, France). The intra-assay CV and interassay CV were 15 and $11 \%$, respectively, for a concentration of $35 \mu \mathrm{IU} / \mathrm{mL}$.

GLP-1 content was extracted from ileal mucosa, cecum, and colon by homogenization of $1 \mathrm{~g}$ of tissue in $5 \mathrm{~mL}$ of ethanol acid solution ( $1 \% \mathrm{HCl} 12 \mathrm{M}, 74 \%$ absolute ethanol, $25 \% \mathrm{H}_{2} \mathrm{O}$ ) (Polytron 3100, Kinematica, 24,000 rpm, $2 \times 20 \mathrm{~s}$ ). After $24 \mathrm{~h}$ at $4^{\circ} \mathrm{C}$, samples were centrifuged $\left(20 \mathrm{~min}, 2,000 \mathrm{~g}, 4^{\circ} \mathrm{C}\right)$, and supernatants diluted $(1: 1,000,1: 300$, and 1:250 for ileal mucosa, cecum, and colon, respectively). Intestinal and plasma GLP1 concentration was measured using a GLP-1 active enzymelinked immunosorbent assay kit (Millipore), according to the manufacturer's instructions.

\section{In vitro STC-1 Cell Assays}

This assay aimed to evaluate in vitro the impact of jejunal and ileal contents on the GLP-1 secretion of STC-1 cells, a murine intestinal tumor cell line that possesses many features of native intestinal enteroendocrine cells. The intestinal STC-1 cell line was obtained from ATCC (ATCC ${ }^{\circledR}$, CRL-3254 ${ }^{\mathrm{TM}}$ ). The STC1 cells were grown $\left(37^{\circ} \mathrm{C}, 5 \% \mathrm{CO}_{2}\right.$ atmosphere) in Dulbecco modified Eagle medium (4.5 g/L glucose) supplemented with $10 \%$ inactivated fetal calf serum (FCS), $100 \mathrm{U} / \mathrm{mL}$ penicillin, $100 \mu \mathrm{g} / \mathrm{mL}$ streptomycin, and $2 \mathrm{mM}$ glutamine. When reaching $80 \%$ confluence, cells were washed with PBS ( $\mathrm{pH} 7.4$ ), trypsinized, and seeded onto 24-well culture plates at a density of $40 \times 10^{3}$ cells per well and cultivated until they reached $70 \%-80 \%$ confluence. Cells were washed twice with media without FCS. Jejunal and ileal digesta were diluted (1:16 vol/vol) in incubation buffer $\left(4.5 \mathrm{mM} \mathrm{KCl}, 1.2 \mathrm{mM} \mathrm{CaCl}_{2}, 1.2 \mathrm{mM} \mathrm{MgCl}_{2}\right.$, $140 \mathrm{mM} \mathrm{NaCl}$, and $20 \mathrm{mM}$ HEPES-Tris, $\mathrm{pH}$ 7.4) and centrifuged $\left(10 \mathrm{~min}, 2,000 \mathrm{~g}, 4^{\circ} \mathrm{C}\right)$. Cells were then incubated for $2 \mathrm{~h}\left(37^{\circ} \mathrm{C}\right.$, $5 \% \mathrm{CO}_{2}$ atmosphere) with the digesta supernatants or with the incubation buffer (control wells). Finally, cell supernatants were collected, centrifuged $\left(7 \mathrm{~min}, 2,000 \mathrm{~g}, 4^{\circ} \mathrm{C}\right)$, and kept at $-20^{\circ} \mathrm{C}$ before GLP-1 radioimmunoassay measurement using an active GLP-1 kit (GLP1A-35HK, EMD Millipore, Billerica, MA, USA).

\section{Statistical Analysis}

Statistical analyses were performed using the R software, version 3.0.3 (27). Normality was tested with Shapiro and Wilk test. For parameters with unequal variances between groups, BoxCox transformations were used. Differences between groups were assessed using a two-way analysis of variance (ANOVA) (lm function) testing formula composition, replication, sex, and interactions between formula and sex, and between formula and replication, followed by Tukey post hoc test (Tukey honestly significant difference). For lipid class characterization across intestinal sites, data were Box-Cox transformed and subjected to ANOVA for repeated measures (lme function) including formula, intestinal site, replication, sex, and interactions between formula and all other factors, followed by Tukey post hoc test (lsmeans package). Sex effect and the diet $\times$ sex interaction were not significant unless otherwise mentioned. Data are presented as mean values with their standard error of the mean (SEM). Differences were considered significant at $p<0.05$ and a trend at $p<0.1$. The graphical representation of the position and abundance of the peptides on the parent protein was performed using an in-house R script.

\section{RESULTS}

\section{Effects of the Addition of Dairy Lipids and Probiotic Lf on Infant Formula and Digestive Content Structures}

The three infant formulas were all characterized by a bimodal distribution of the particle size in water (Figure 1A, mode $1=$ 
A

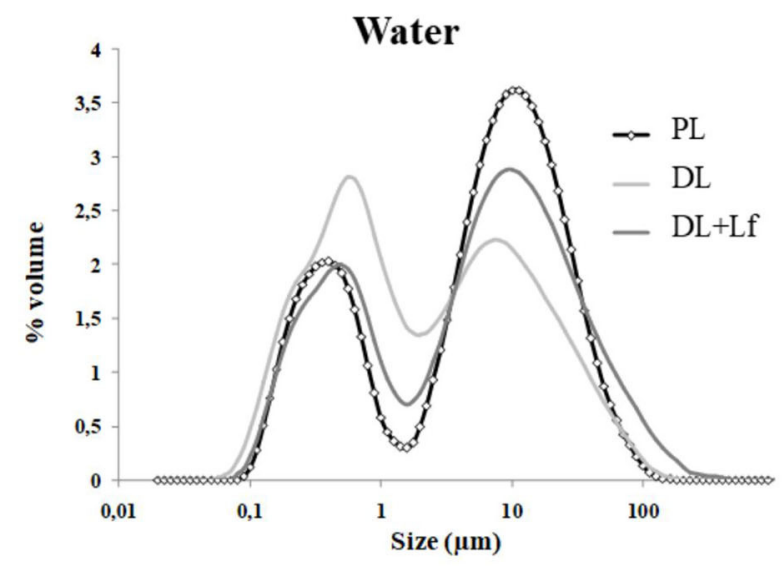

B

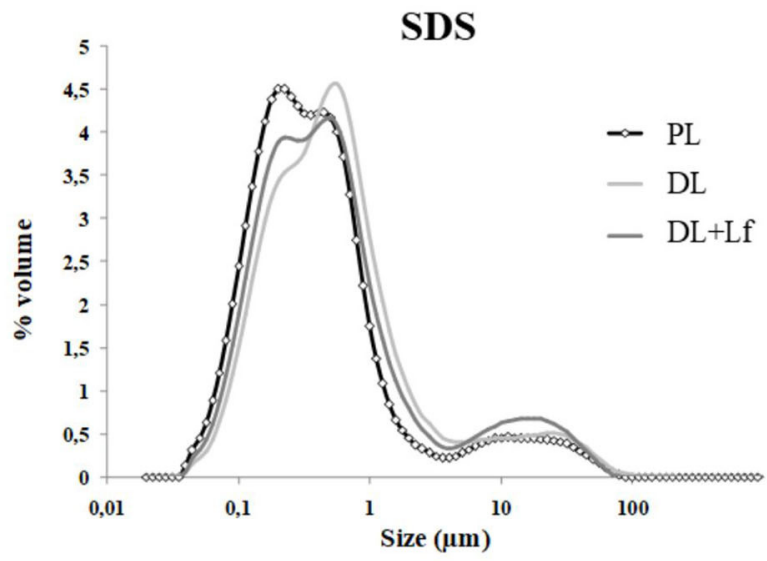

c

Formula

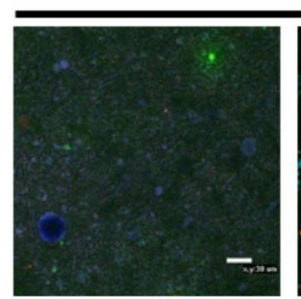

PL

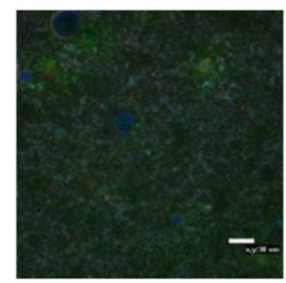

DL

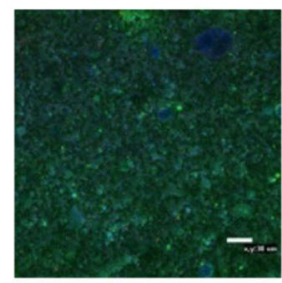

Stomach
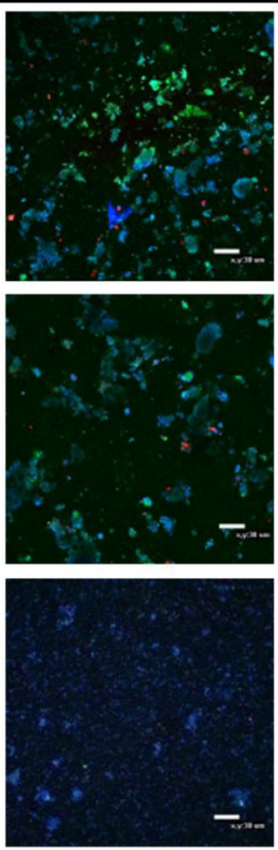

Jejunum
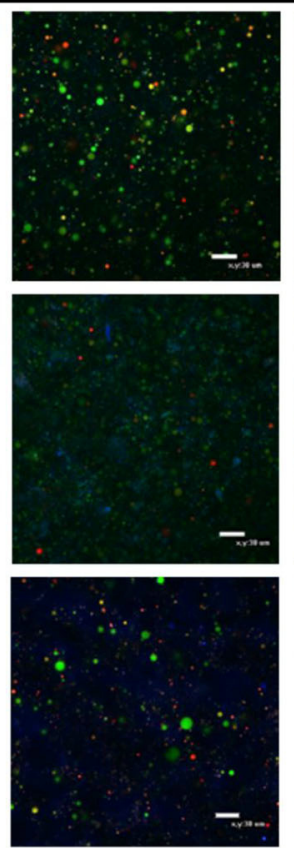

Ileum

Colon
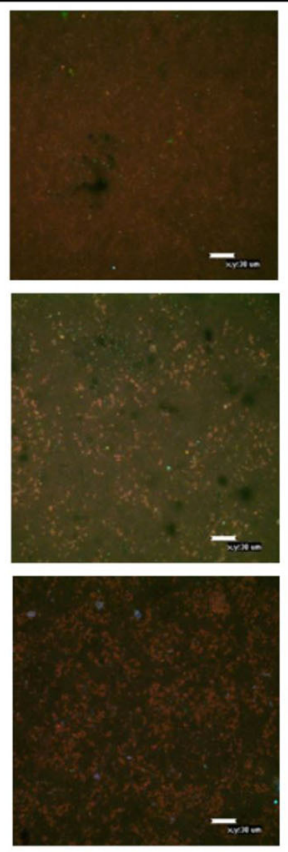
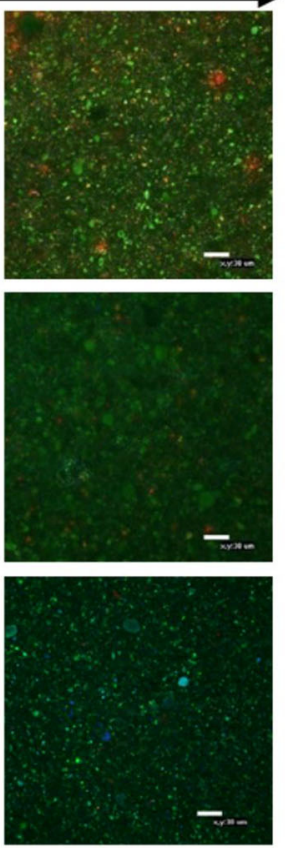

FIGURE 1 | Structural characterization of PL, DL, and DL+Lf formulas. (A,B) Particle size distribution of undigested PL, DL, and DL+Lf formulas determined by laser light scattering in (A) water and (B) SDS. Data represent the mean of three samples, each of them being measured in triplicate. (C) Confocal laser scanning microscopy images (objective $\times 40$ zoom 1) of PL, DL, and DL+Lf undigested formulas and digestive contents from stomach to colon. Apolar lipids are colored in green (Lipidtox ${ }^{\circledR}$ ), amphiphilic compounds in red (Rhodamine-PE ${ }^{\circledR}$ ), and proteins in blue (fast green). Scale bars $=30 \mu \mathrm{m}$. Formulas contained as lipids either only plant lipids $(\mathrm{PL})$, a half-half mixture of plant and dairy lipids $(\mathrm{DL})$, or a half-half mixture of plant and dairy lipids supplemented with $L f(D L+L f)$ sulfate.

$9.77 \mu \mathrm{m}$ and mode $2=0.52 \mu \mathrm{m}$ ). The biggest mode (mode 1 ) mostly disappeared after SDS addition (Figure 1B), indicating that these larger particles were aggregated droplets.

The microstructure of the digestive contents $90 \mathrm{~min}$ postprandially is given in Figure 1C. There was no major difference among formula groups within an intestinal site, whereas differences between intestinal sites were observed. The gastric phase was dominated by strong emulsion destabilization and protein aggregation. Lipid droplets were inserted within protein aggregates, which were likely formed due to the combined effect of acidic $\mathrm{pH}$ (3.4 in average at $90 \mathrm{~min}$ postprandially, Table 2 ) and proteolysis. The digesta 
TABLE 2 | Digestive contents $\mathrm{pH}$ of $\mathrm{PL}, \mathrm{DL}$, and $\mathrm{DL}+\mathrm{Lf}$ formulas.

\begin{tabular}{lcccc}
\hline pH & PL & DL & DL+Lf & $\begin{array}{c}\text { Diet effect } \\
\boldsymbol{p} \text { value }\end{array}$ \\
\hline Stomach & $3.41 \pm 0.30$ & $3.37 \pm 0.45$ & $3.39 \pm 0.30$ & 0.98 \\
Duodenum & $4.64 \pm 0.20$ & $4.74 \pm 0.30$ & $4.80 \pm 0.23$ & 0.90 \\
Proximal jejunum* & $5.66 \pm 0.15$ & $5.42 \pm 0.12$ & $5.48 \pm 0.13$ & 0.17 \\
Median jejunum & $6.66 \pm 0.10$ & $6.90 \pm 0.06$ & $6.65 \pm 0.14$ & 0.20 \\
Ileum & $7.64 \pm 0.11$ & $7.72 \pm 0.10$ & $7.66 \pm 0.15$ & 0.46 \\
\hline
\end{tabular}

Data are expressed as the mean \pm SEM. ${ }^{*}$ Proximal jejunum: $p(s e x)<0.01$ (females > males).

Formulas contained as lipids either only plant lipids ( $P L, n=5-8$ ), a half-half mixture of plant and dairy lipids (DL, $n=5-7)$, or a half-half mixture of plant and dairy lipids supplemented with $L f(D L+L f, n=4-7)$.

structure in jejunum greatly differed from that in the stomach, with fewer protein aggregates likely due to the digestive process (hydrolysis, emptying, and dilution by endogenous fluids) combined with the $\mathrm{pH}$ increase (Table 2). Mixed droplets of apolar and amphiphilic compounds, created by the bile salt emulsification, were also observed in the jejunum. There was mainly a colocalization of apolar lipids and amphiphilic molecules in the ileum (Figure 1C). The digesta structure in the colon was different from that of the ileum, with great quantity of apolar lipids, possibly originating from undigested lipids of the infant formula.

Gastric $\mathrm{pH}$ and intestinal pH (Table 2) were not impacted by the formula composition, increasing from the stomach up to the ileum.

\section{Effects of the Addition of Dairy Lipids and Probiotic Lf on Piglet Growth, Body Composition, and Intestinal Morphology}

BW gain, energy intake, and food efficiency were similar between groups during the lactation period (Supplementary Figures 1A-C). BW at euthanasia and tissue relative weights were similar between groups except for the liver $(\mathrm{DL}>\mathrm{PL}$ ), duodenum (tendency DL $+\mathrm{Lf}>\mathrm{DL}$ ), and the median jejunum (DL+Lf $>$ PL and DL) (Supplementary Table 1). Total small intestinal length tended to be higher in DL+Lf compared with DL. Goblet cell number was higher in the proximal jejunum of DL+Lf than PL piglets, whereas villi surface tended to be lower in the ileum of DL+Lf than PL piglets (Supplementary Table 1); neither was different to DL.

\section{Effects of the Addition of Dairy Lipids and Probiotic Lf on Proteolysis}

Gastric protein digestion was followed by SDS-PAGE (Figure 2A). Regardless of the formula, casein was more extensively digested than $\beta$-lactoglobulin and $\alpha$-lactalbumin $90 \mathrm{~min}$ postprandially (Figure 2A). The percentage of intact casein was lower in DL+Lf stomach compared with PL and $\mathrm{DL}$, highlighting a decreased resistance of this protein to gastric digestion in the presence of DLs and probiotic Lf (Figure 2A). Intact protein percentages of $\beta$-lactoglobulin and $\alpha$-lactalbumin were similar between groups. The overall gastric protein hydrolysis was higher in DL and DL+Lf piglets than in PL piglets (Figure 2B).

Overall, before and during digestion, 2,758 unique peptides (6-46 amino acids in length) were identified and derived from 19 parent proteins, of whom 8 were caseins (Supplementary Table 2). Forty to sixty peptides, mainly derived from caseins, were identified before digestion in the three infant formulas.

Of the 2,758 identified peptides, 1,954 peptides (still originating from the aforementioned 19 parent proteins, Figure 3) were kept for further analyses because they were present in at least half (or half +1 in case of odd number) of the digesta samples of one of the three groups at a given site. Peptide diversity was the highest in the stomach and in proximal jejunum and largely decreased in the lowest part of the intestine (Figure 3). A large percentage of peptides were common between consecutive digestive sites, especially between proximal and the median jejunum (Figure 3). Throughout digestive sites, peptides mainly originated from $\beta$-casein (CSN2A2) and $\beta$-lactoglobulin (BLGA) (Figure 3). Distribution of peptides along these parent protein sequences was similar between groups in the stomach until the median jejunum but was more different in the ileum and the colon (Figure 4). The average peptide abundance of $\beta$ lactoglobulin and $\beta$-casein was the highest for PL and the lowest for DL+Lf from stomach to median jejunum, whereas a higher peptide abundance was observed in ileum for DL and in colon for DL + Lf especially on $\beta$-casein (Figure 4).

The number of identified bioactive peptides and AMPs was the highest in the stomach (Figure 3). Some bioactive peptides and potential AMPs were still found in proximal jejunum, but a reduced number (maximum of 4) were observed from median jejunum to the colon. Bioactive peptides originated from $\beta$-lactoglobulin, $\beta$-casein, $\alpha$-s1 and $\alpha$-s 2 casein, and $\kappa$-casein in the stomach; from $\beta$ lactoglobulin, $\beta$-casein, $\alpha$-s1 and $\alpha$-s 2 casein, and $\alpha$-lactalbumin in the proximal jejunum; and from $\beta$-casein in the median jejunum, ileum, and colon. One peptide originated from $\alpha$-s1 casein in DL+Lf ileum. Throughout the digestive sites, identified bioactivities were antibacterial, immunomodulating, dipeptidyl peptidase IV inhibitor, angiotensin-converting enzyme inhibitor, antiamnestic, binding, hamolytic, anticancer, opioid agonist, and antioxidative. Predicted AMPs originated from $\beta$-lactoglobulin, $\alpha$-s1 and $\alpha$-s2 casein, $\kappa$-casein, xanthine dehydrogenase/oxidase, lactoperoxidase, osteopontin, and serum albumin in the stomach; $\beta$-lactoglobulin and $\beta$-casein in proximal jejunum; and $\beta$-lactoglobulin in median jejunum, ileum, and colon. Bioactive peptides and predicted AMPs originating from the two major proteins, $\beta$-lactoglobulin and $\beta$-casein, are presented in Figure 4; for clarity, gastric AMPs are not shown.

\section{Effects of the Addition of Dairy Lipids and Probiotic Lf on Lipolysis}

Fatty acid composition of the infant formulas is given in Figure 5. Except for trans-fatty acid content, the three infant 
A

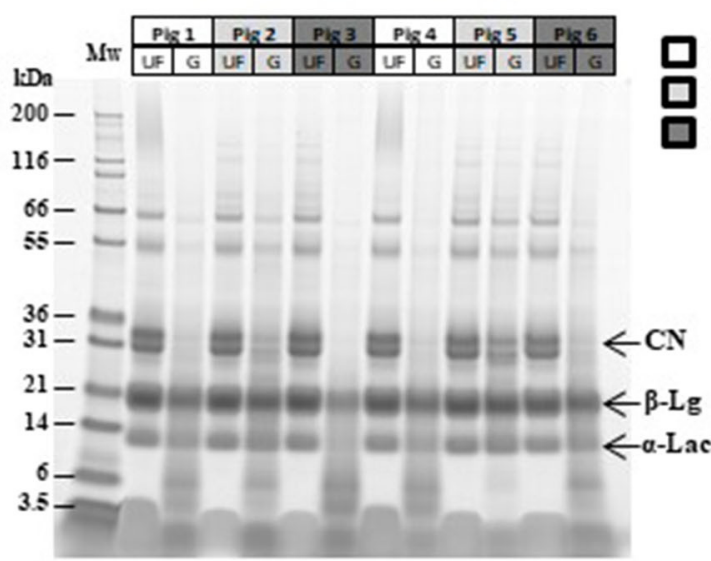

PL formula

DL formula

DL+Lf formula

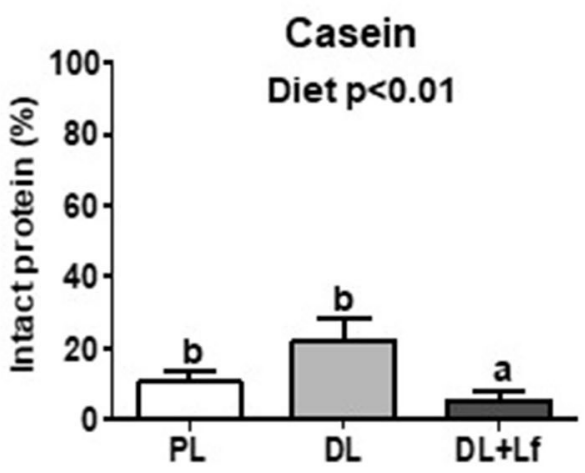

$\boldsymbol{\beta}$-lactoglobulin

a-lactalbumin
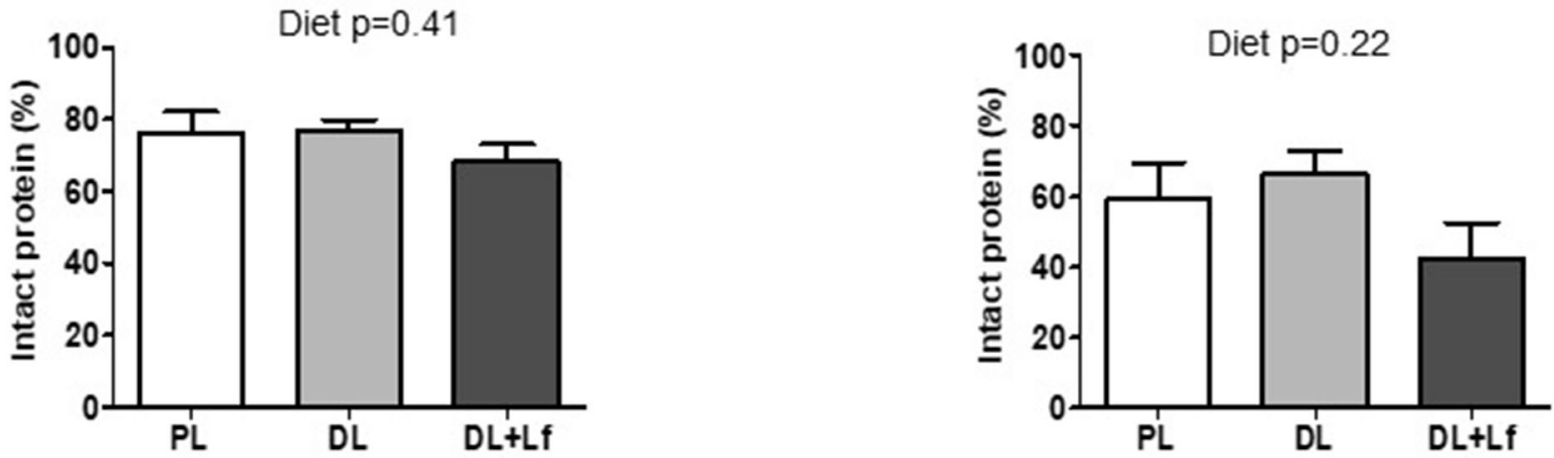

B

Gastric protein hydolysis

Diet $\mathrm{p}=0.01$

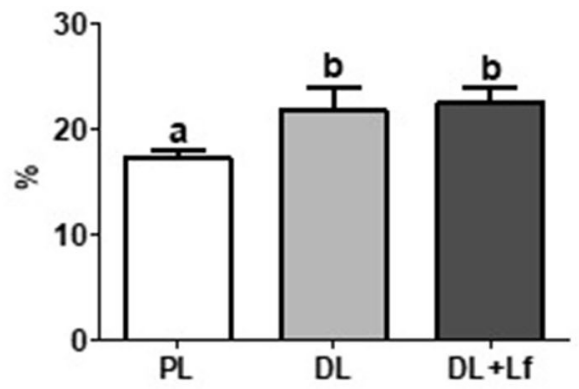

FIGURE 2 | Gastric proteolysis of PL, DL, and DL+Lf formulas. (A) Example of SDS-PAGE protein profiles of PL, DL, and DL+Lf formulas during gastric in vivo digestion. Protein molecular mass standards (Mw) are on the left followed by the undigested infant formula (UF) and corresponding gastric content (G) for the same pig (side by side). Gastric proteolysis resistance: corresponding percentage of intact proteins [casein (CN), $\beta$-lactoglobulin ( $\beta$-Lg), and $\alpha$-lactalbumin ( $\alpha$-Lac)] during gastric digestion, estimated by densitometry in comparison to the corresponding undigested formula. Data are expressed as the mean \pm SEM. Labeled means without a common letter differ $(p<0.05)$. (B) Gastric proteolysis evaluated by NH2 quantification. Formulas contained as lipids either only plant lipids (PL, $n=7-8)$, a half-half mixture of plant and dairy lipids (DL, $n=6-8$ ), or a half-half mixture of plant and dairy lipids supplemented with Lf (DL+Lf, $n=6$ ). SDS-PAGE, sodium dodecyl

sulfate-polyacrylamide gel electrophoresis; CN, casein; $\beta$-Lg, $\beta$-lactoglobulin; $\alpha$-Lac, $\alpha$-lactalbumin. 
PL

\section{Stomach}

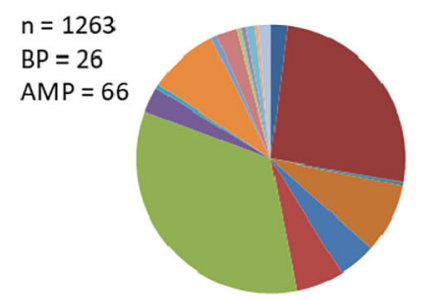

\section{Proximal}

\section{jejunum}

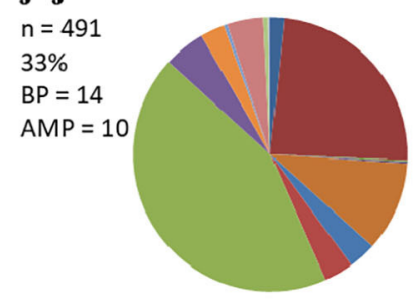

\section{Median}

\section{jejunum}
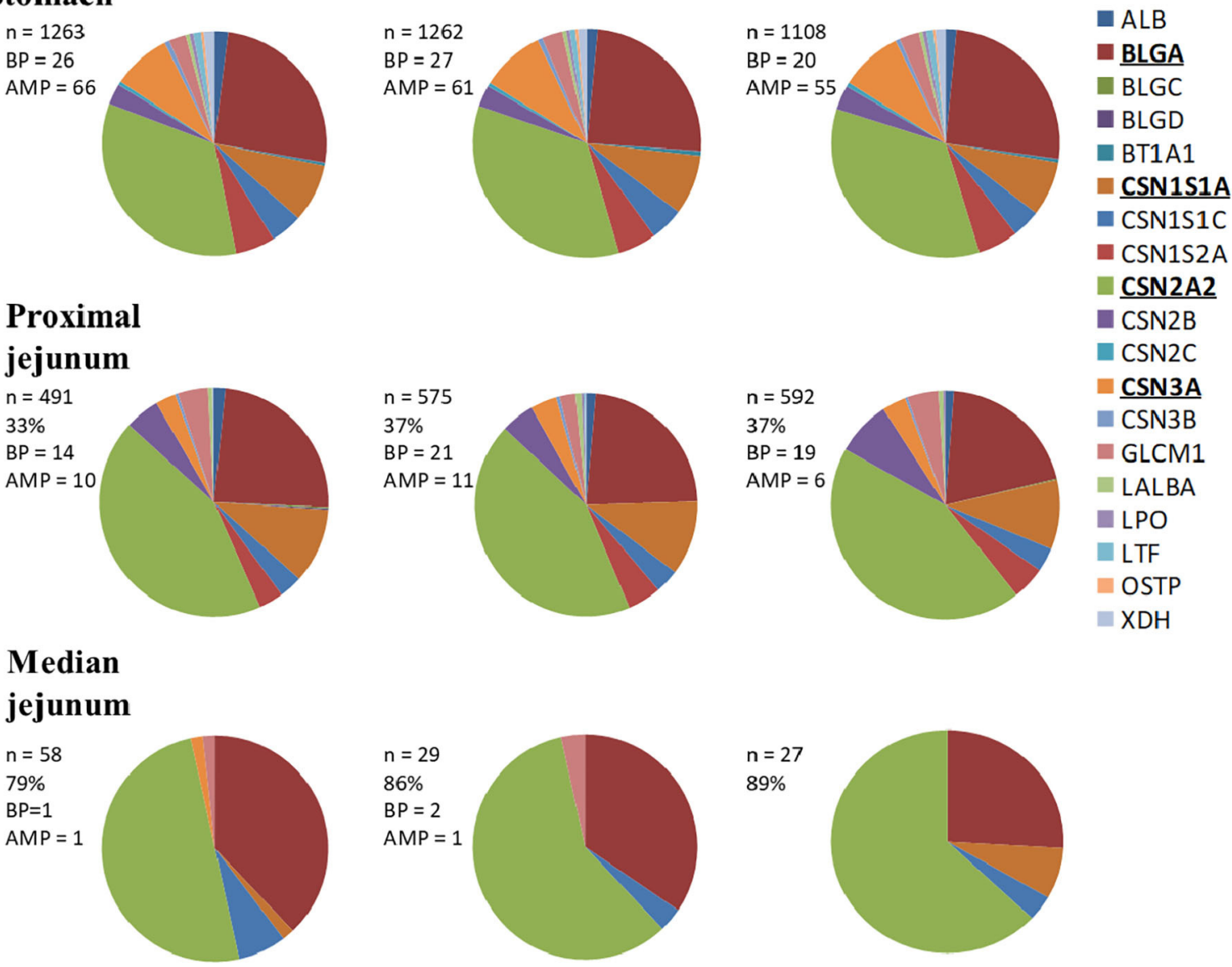

$\mathrm{n}=27$

$89 \%$

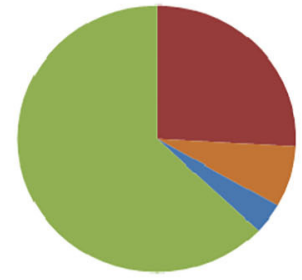

\section{Ileum}

$\mathrm{n}=7$

$59 \%$
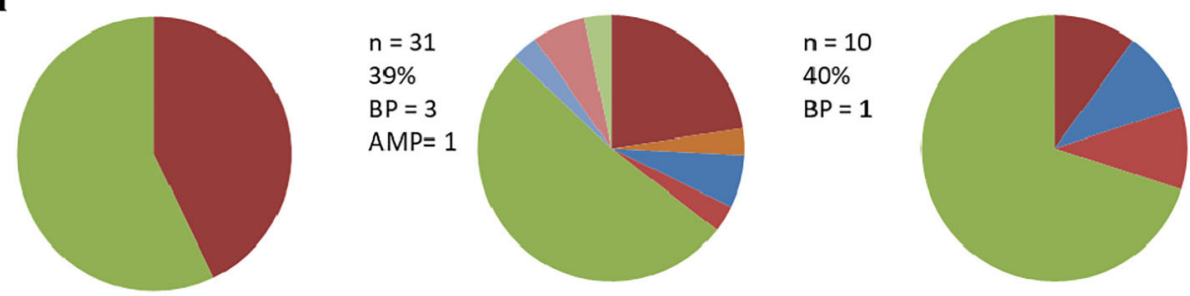

\section{Colon}
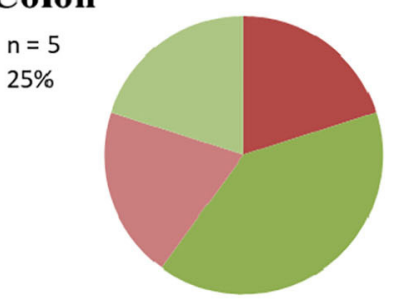
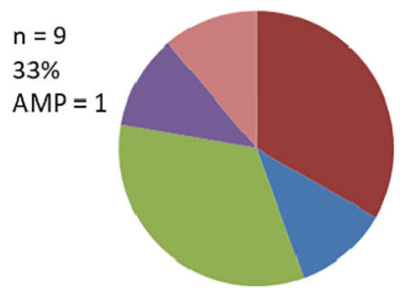
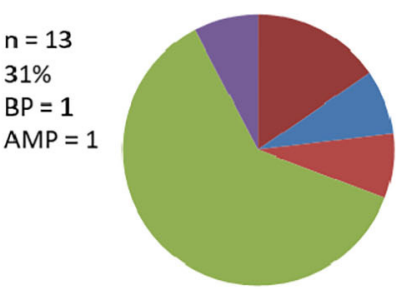

FIGURE 3 | Pie chart distributions of peptides by parent proteins throughout the gastrointestinal tract. Proteins that appear in bold and underlined are the main parent proteins. In the insert, the following information are given: $\mathrm{n}$, number of peptides; \%, \% of peptides common with the preceding compartment; BP, bioactive peptides; AMP, predicted anti-microbial peptides. Formulas contained as lipids either only plant lipids (PL, $n=5-8)$, a half-half mixture of plant and dairy lipids (DL, $n=5-8)$, or 
FIGURE 3 | a half-half mixture of plant and dairy lipids supplemented with $\mathrm{Lf}(\mathrm{DL}+\mathrm{Lf}, n=6-7)$. ALB, serum albumin; BLGA, $\beta$-lactoglobulin A; BLGC, $\beta$-lactoglobulin C; BLGD, $\beta$-lactoglobulin D; BT1A1, butyrophilin; CSN1S1A, casein $\alpha$-S1 A; CSN1S1C, casein $\alpha$-S1 C; CSN1S2A, casein $\alpha$-S2 A; CSN2A2, $\beta$-casein A2; CSN2B, $\beta$-casein B; CSN2C, $\beta$-casein C; CSN3A, $к$-casein A; CSN3B, $\kappa$-casein B; GLCM1, glycosylation-dependent cell adhesion molecule; LALBA, $\alpha$-lactalbumin; LPO, lactoperoxydase; LTF, lactoferrin; OSTP, osteopontin; XDH, xanthine dehydrogenase/oxidase.

formulas had similar content of the different classes of fatty acids (saturated and unsaturated fatty acids). However, the main individual fatty acids greatly differed among formulas, with higher levels of $\mathrm{C} 18: 1$ and $\mathrm{C} 16: 0$ and lower levels of C18:0 and C14:0 in PL than in DL and DL+Lf. As expected, the PL formula containing only vegetable lipids merely contains fatty acids ranging from $\mathrm{C} 6: 0$ to $\mathrm{C} 10: 0$, also called medium-chain fatty acids (MCFAs), and DL and DL+Lf formulas incorporating DLs as cream contained much more of these MCFAs.

Gastric lipolysis degree was very low $(<1 \%)$ and similar for all three groups. Along the digestive tract, lipolysis increased from the stomach to the ileum $90 \mathrm{~min}$ postprandially and was characterized by a strong decrease in triacylglycerols and an increase in lipolysis products (FFAs and diacylglycerols and monoacylglycerols) (Figure 6A). The kinetics of appearance of diacylglycerols/cholesterol were significantly impacted by the infant formula composition, depending on the intestinal site (Figure 6B). A higher percentage of diacylglycerols/cholesterol was observed in DL stomach and in DL and DL+Lf proximal jejunum and ileum compared with PL. Regardless of formula, this percentage was increased in the proximal jejunum compared with the stomach and decreased in the ileum compared with the proximal jejunum. The kinetics of appearance of FFAs and monoacylglycerols/polar lipids in small intestinal contents were not significantly different amongst formulas (data not shown). The triacylglycerols:total lipid ratio in proximal jejunum was similar between groups (Figure 6C). In contrast, it tended to decrease in DL+Lf ileum compared with PL (Figure 6D), reflecting an increased lipolysis.

\section{Effects of the Addition of Dairy Lipids and Probiotic Lf on Metabolism and Entero-Insular Axis}

The infant formula composition barely influenced the plasma lipid profile with tendencies to decrease plasma FFA and triglyceride concentrations in DL and DL+Lf piglets compared with PL (Figure 7A) and did not influence plasma glucose, insulin, and insulin:glucose ratio, and GLP-1 and haptoglobin concentrations (Figures 7B-D). The percentage of endocrine tissue and the number of Langerhans islets in the pancreas were decreased in DL+Lf compared with DL with no effect on the pancreas insulin content (Table 3). Mean islet diameter tended to be increased in DL compared with PL and DL+Lf (Table 3) without any difference in the pancreatic size islet distribution (data not shown). However, the infant formula composition had no effect on GLP-1 concentration and GLP1 -secreting cell number in the ileum, cecum, and colon (Supplementary Table 3). Finally, the capacity of jejunal and ileal contents to induce GLP-1 secretion by STC-1 cells did not significantly differ between formulas (Figure 8).

\section{DISCUSSION}

To our knowledge, this is the first study evaluating the impact of the addition of DLs with or without probiotic Lf in infant formulas on digestion, gut physiology, and metabolism. This study demonstrated, through the use of a set of multiscale techniques, that the addition of DLs and probiotic Lf in infant formulas affected protein and lipid digestion, decreased the endocrine tissue in the pancreas, and increased the intestine weight and the jejunal goblet cell density in Yucatan minipiglets.

A classical structure of homogenized infant formulas was observed with submicronic fat droplets in all the formulas, although most of them were in an aggregated form in the three formulas, as observed after the addition of an anionic surfactant. The observed microstructure in digesta differed alongside the digestive tract, but was not different among formulas with the present magnification. Different interfacial composition between DLs and PLs may have been present; however, interface characterization was not performed. This could be achieved after extracting and washing the lipid droplets, followed by chromatography characterization of proteins and phospholipids at the interface.

The infant formula composition affected the overall gastric proteolysis that was increased in the two groups that received DLs, potentially resulting from different interfacial composition between dairy and plant lipids. This result was in line with the lower concentration of residual intact caseins in DL+Lf stomach, but not with that in DL stomach. The former observation could be partly induced by a faster gastric emptying, as the fraction of the ingested meal remaining in stomach $90 \mathrm{~min}$ postprandially was the lowest in DL+Lf compared to DL and PL (24 vs. 33 and 36\%, respectively), although this did not reach statistical significance. The values obtained for DL and $\mathrm{PL}$ were in agreement with previous results indicating that $39 \%$ of total ingested nitrogen remained in the stomach $90 \mathrm{~min}$ postprandially, vs. $79 \% 30 \mathrm{~min}$ after meal ingestion (16). It is unlikely that the increased proteolysis was related to a proteolytic effect of the probiotic Lf since Cardenas et al. (28) did not reveal a remarkable proteolytic activity of probiotic Lf.

Caseins, particularly $\beta$-casein, were identified in our study as the main parent protein of the peptides present in the three experimental formulas and in digestive contents. Differences in protein digestion and casein resistance previously discussed may therefore affect the release of peptides and protein/peptide biological activities. In agreement with the decreased intact casein in the DL+Lf stomach, peptides belonging to $\beta$-casein were less abundant in the stomach and proximal and median jejunum but more abundant in the colon of DL+Lf than in that of PL and DL. This result is in accordance with a faster gastric emptying induced by dairy lipids and probiotic Lf. Different bioactive peptides were observed along the sequence of $\beta$-casein 

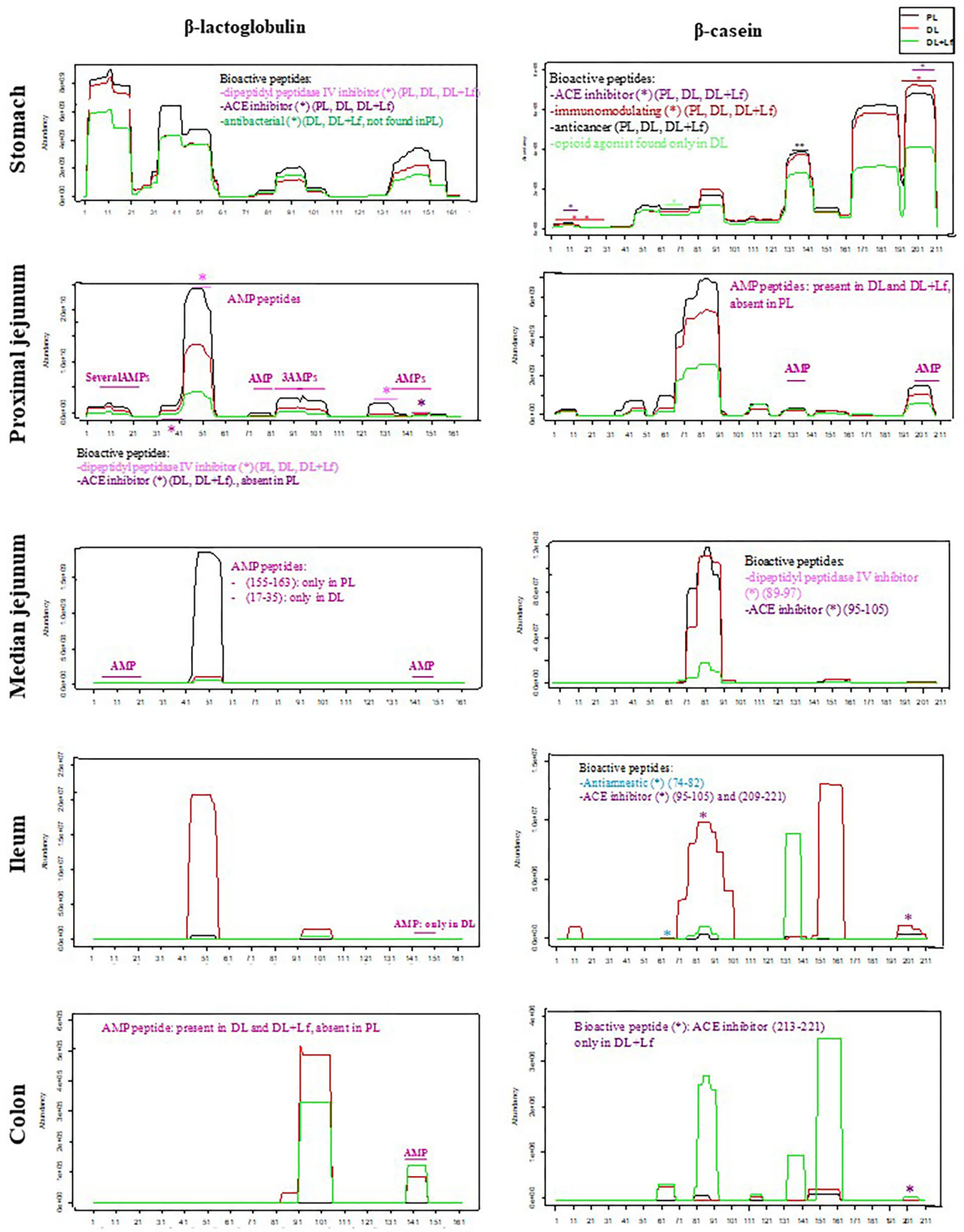

FIGURE 4 | Abundance of peptides belonging to $\beta$-lactoglobulin (BLGA) and $\beta$-casein (CSN2A2) proteins and identification of bioactive peptides and AMPS throughout the gastrointestinal tract. Bioactive peptides and AMPs are identified by a star colored according to their predicted bioactivity. Formulas contained as lipids either only plant lipids ( $\mathrm{PL}, n=5-8$ ), a half-half mixture of plant and dairy lipids ( $\mathrm{DL}, n=5-8$ ), or a half-half mixture of plant and dairy lipids supplemented with $\mathrm{Lf}$ $(\mathrm{DL}+\mathrm{Lf}, n=6-7)$. A * indicates bioactive peptide or AMP peptides. AMP, antimicrobial peptide; ACE, angiotensin-converting enzyme. 


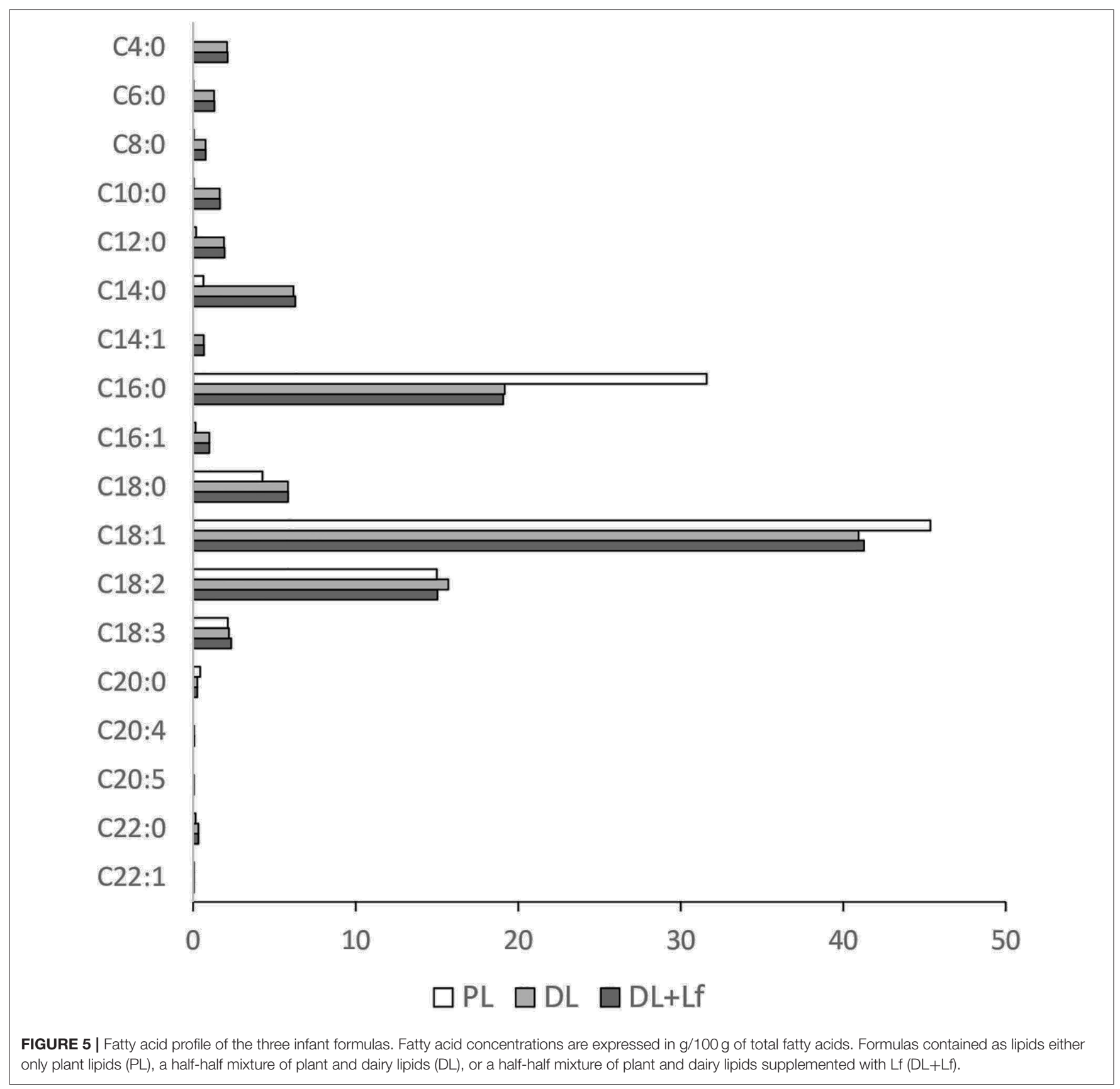

and $\beta$-lactoglobulin. Particularly, an inhibitor of the DPP-IV was found to be less abundant for DL + Lf than for the other formulas from the stomach until the median jejunum. The DDP-IV is produced all along the intestine, and significant DPP-IV-like activity occurs in the microbiota (29). This peptidase is involved in the last step of dietary protein digestion, with the specificity of being able to hydrolyze peptides containing proline, unlike pancreatic proteases. Thus, the reduction of DPP-IV activity may alter protein digestion and absorption (29). Besides, DPP-IV is known to inactivate two incretins, GLP-1 and GIP, involved in the control of glucose metabolism. In the present study, such effect was not apparent as plasma GLP-1 contents were similar among groups. This can be explained by the fact that the DPP-IV activity in the bloodstream is mainly that of hematopoietic and endothelial cells.

Different distributions of peptide origin were observed between groups from median jejunum to colon. Especially, PL had lower peptide diversity in the ileum and the colon compared to DL and DL + Lf, highlighting a specific effect of dairy lipids on proteolysis. These different peptides may differentially modulate gut microbiota and gut physiology, or on the other hand, dairy lipids and probiotic Lf may have differentially modulated gut 


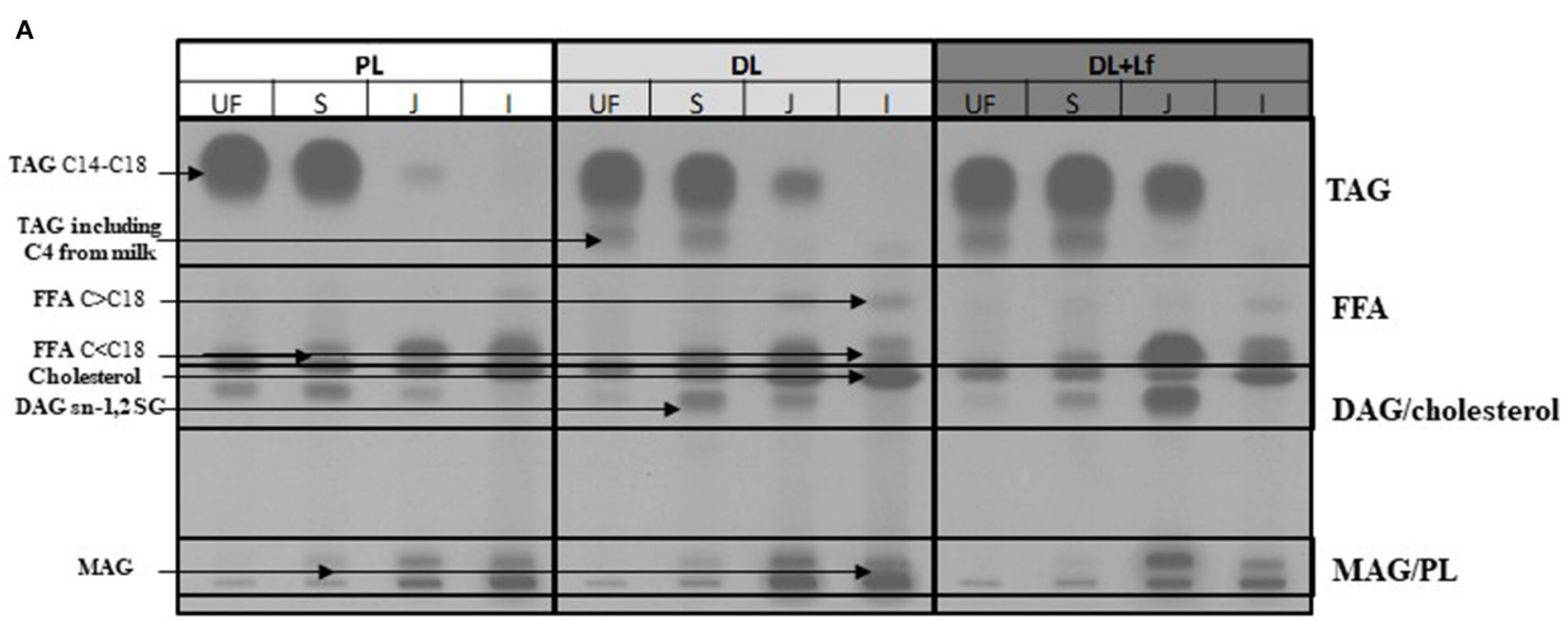

B

\section{DAG/cholesterol *}

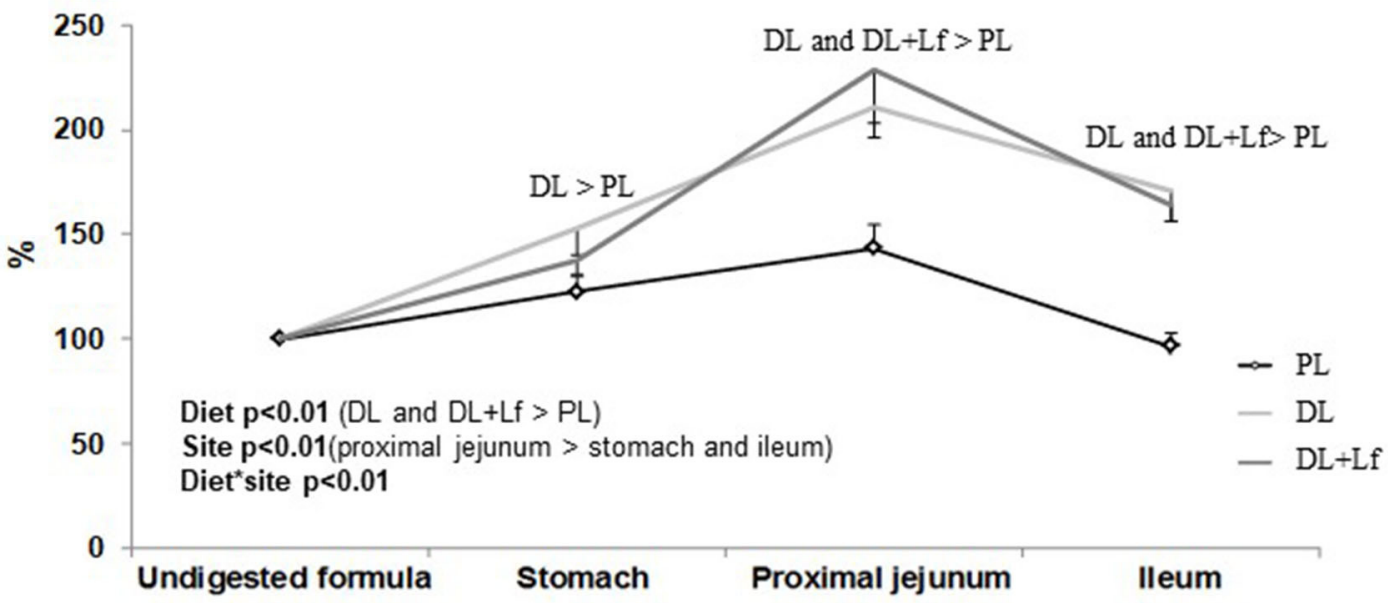

C

\section{Triacylglycerols / total lipids ratio Proximal jejunum *}

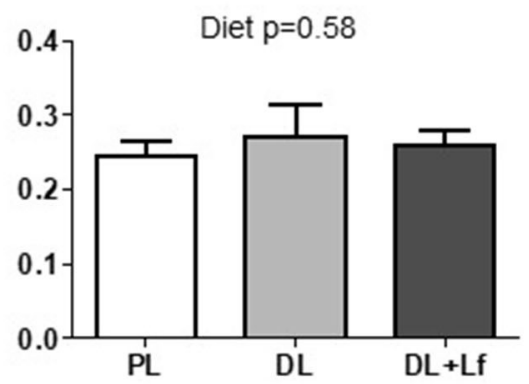

D

Triacylglycerols / total lipids ratio lleum

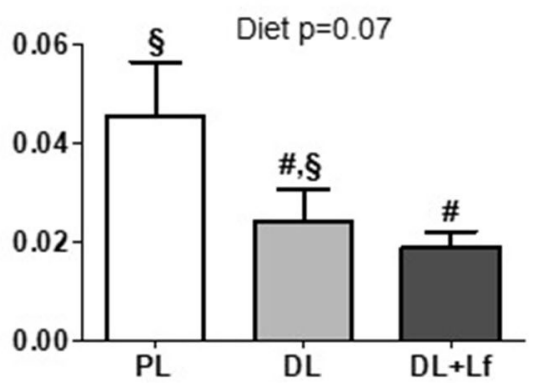

FIGURE 6 | Gastric and intestinal lipolysis of PL, DL, and DL+Lf formulas. (A) Example of thin-layer chromatography showing the evolution of lipid classes between stomach (S), proximal jejunum (J), and ileum (I) 90 min postprandially compared to undigested formula (UF). (B) Longitudinal evolution of DAG/cholesterol along the intestine based on the undigested infant formula content. All written effects were significant $(p<0.01)$. (C) Triacylglycerols/total lipids ratio in proximal jejunum and 
FIGURE 6 | (D) in ileum. Labeled bar charts without a common symbol differ $(p<0.1)$. Formulas contained as lipids either only plant lipids (PL, $n=7-8)$, a half-half mixture of plant and dairy lipids (DL, $n=6-8$ ), or a half-half mixture of plant and dairy lipids supplemented with $L f(D L+L f, n=6-7$ ). TAG, triacylglycerol; FFA, free fatty acids; SC, short chain; DAG, diacylglycerol; MAG, monoacylglycerol; PL, polar lipid. Data are expressed as the mean $\pm \mathrm{SEM}$. *DAG/cholesterol: $p($ diet * sex) $=0.04$ $(\mathrm{DL}$ and $\mathrm{DL}+\mathrm{Lf}$ females $>\mathrm{PL}$ females, $\mathrm{DL}$, and $\mathrm{DL}+\mathrm{Lf}$ male piglets $>\mathrm{PL}$ male piglets); TAG/total lipids ratio in proximal jejunum: $p$ (diet * sex) $=0.02$ (DL males $>$ DL females) and $p$ (sex) is not significant.

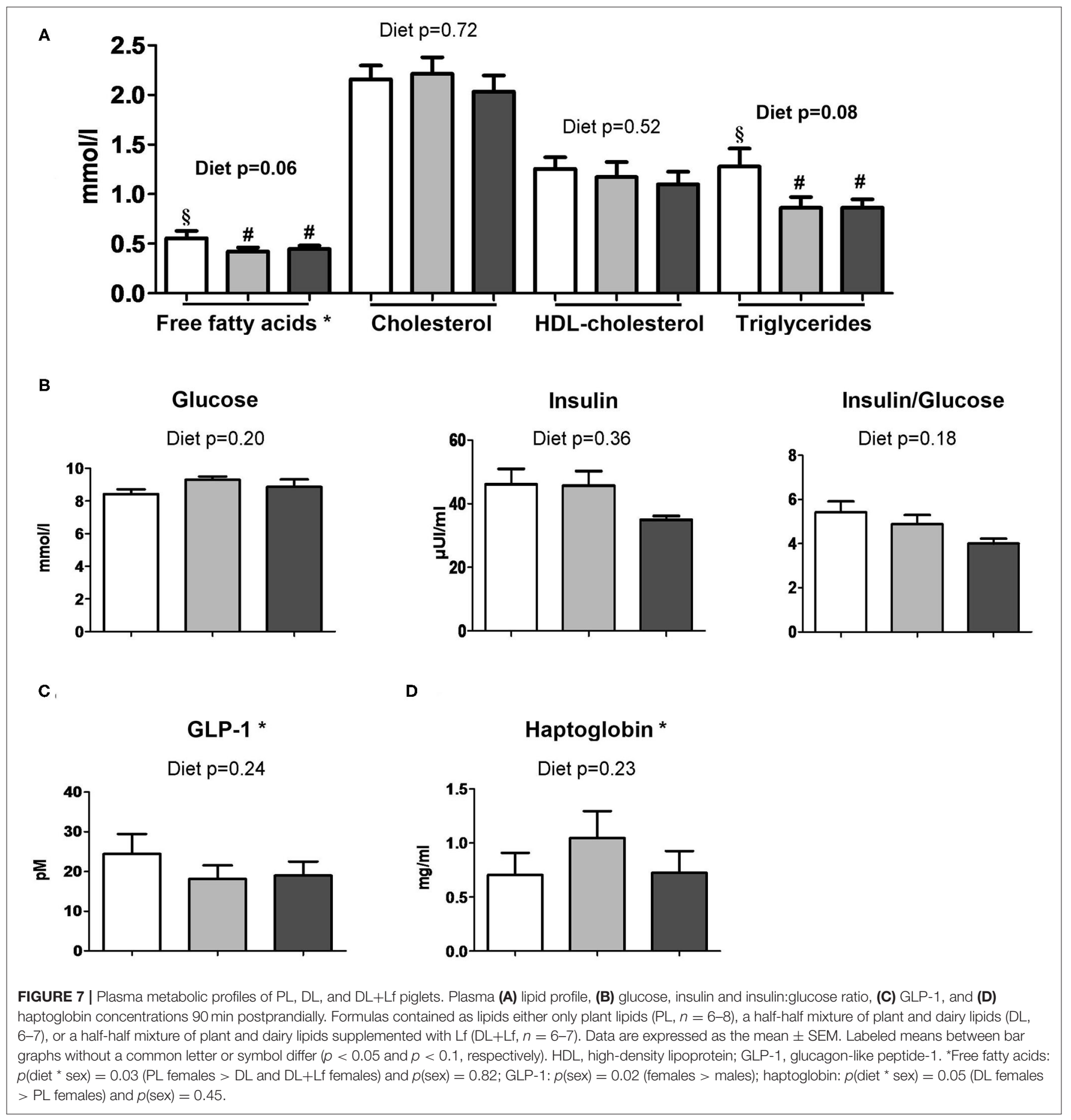

physiology and consequently its digestive capacity. Particularly, the present study has demonstrated a beneficial effect of probiotic Lf on non-specific host defenses, increasing goblet cell density in jejunum, in agreement with Lf-induced greater MUC-2 expression observed in vitro in HT29 cells (30). It should be noted that the intestinal transit time may also have been changed 
TABLE 3 | Endocrine pancreas parameters of PL, DL, and DL+Lf piglets.

\begin{tabular}{lcccc}
\hline $\begin{array}{l}\text { Endocrine } \\
\text { pancreas }\end{array}$ & PL & DL & DL+Lf & $\begin{array}{c}\text { Diet effect } \boldsymbol{p} \\
\text { value }\end{array}$ \\
\hline & & & \\
$\begin{array}{l}\text { Endocrine tissue } \\
\text { (\%) }\end{array}$ & $1.79 \pm 0.17^{\mathrm{a}, \mathrm{b}}$ & $2.28 \pm 0.24^{\mathrm{b}}$ & $1.58 \pm 0.07^{\mathrm{a}}$ & 0.02 \\
$\begin{array}{l}\text { No. of islets } \\
\text { (per 0.5-cm }\end{array}$ & $250 \pm 21^{\mathrm{a}, \mathrm{b}}$ & $291 \pm 22^{\mathrm{b}}$ & $221 \pm 9^{\mathrm{a}}$ & 0.05 \\
tissue) & & & & \\
$\begin{array}{l}\text { Mean islet } \\
\text { diameter ( } \mu \mathrm{m})^{*}\end{array}$ & $54.6 \pm 0.9^{\#}$ & $56.7 \pm 1.2^{\S}$ & $54.7 \pm 0.7^{\#}$ & 0.09 \\
$\begin{array}{l}\text { Insulin content } \\
\text { (IU/g of pancreas) }\end{array}$ & $14.3 \pm 0.5$ & $15.3 \pm 1.3$ & $13.7 \pm 1.0$ & 0.58 \\
\end{tabular}

Data are expressed as the mean $\pm S E M$. Labeled means in a row without a common letter or symbol differ $\left(p<0.05\right.$ and $p<0.1$, respectively). ${ }^{*}$ Endocrine tissue: $p($ sex $)=0.1$ (males > females); endocrine pancreas mean islet diameter: $p$ (sex $)<0.01$ (males $>$ females). Formulas contained as lipids either only plant lipids ( $P L, n=6-8$ ), a half-half mixture of plant and dairy lipids ( $D L, n=6)$, or a half-half mixture of plant and dairy lipids supplemented with $L f(D L+L f, n=6-7)$.

by specific peptides released during casein digestion such as the opioid ones $(31,32)$.

Another important result was that the infant formula composition modulated lipid digestion. This was not apparent at the stomach level, where lipolysis appeared to be low; however, this may have been underestimated because of the gastric emptying of the FFAs released before digesta collection. The percentage of diacylglycerols/cholesterol present at $90 \mathrm{~min}$ postprandially was higher for $\mathrm{DL}$ and $\mathrm{DL}+\mathrm{Lf}$ than for $\mathrm{PL}$ in proximal jejunum and ileum, which is likely due to a higher abundance of diacylglycerols sn-1,2 from DL and DL+Lf compared with PL. Concomitantly, tendencies to decreased plasma FFA and triglyceride concentrations in DL and DL+Lf piglets compared with PL were observed. This could be the result of a different metabolic fate of the lipolysis products and/or a reduced and/or slower lipid absorption with dairy lipids. Differences observed among groups in terms of lipolysis may therefore trigger health effect. In addition, the nature of the fatty acid released can also play different luminal and systemic functions. Our previous study on milk fat and MFGM fragments in piglets showed a significant increase of the mucosal immune system maturation and modification of the fecal microbiota composition (8). Particularly, the sphingosine and MCFAs present in dairy lipids are known for their antimicrobial activity and their modulation of gut microbiota establishment with increased Lactobacillus and Bifidobacterium (33). Contrary to what was expected, no difference in plasma cholesterol was observed between groups. It is noteworthy that the cholesterol content of the experimental formulas containing dairy lipids was lower than that of sow milk [0.80 and $10.7 \mathrm{mg}$ for $100 \mathrm{~mL}$ of PL and $\mathrm{DL}( \pm \mathrm{Lf})$ formulas, respectively, vs. $145 \mathrm{mg}$ for $100 \mathrm{~mL}$ of sow milk (34)].

Overall metabolism was not affected by the infant formula composition. However, our results highlighted that probiotic Lf decreased the percentage of endocrine pancreas and the number of Langerhans islets. Similar effect of "pancreatic

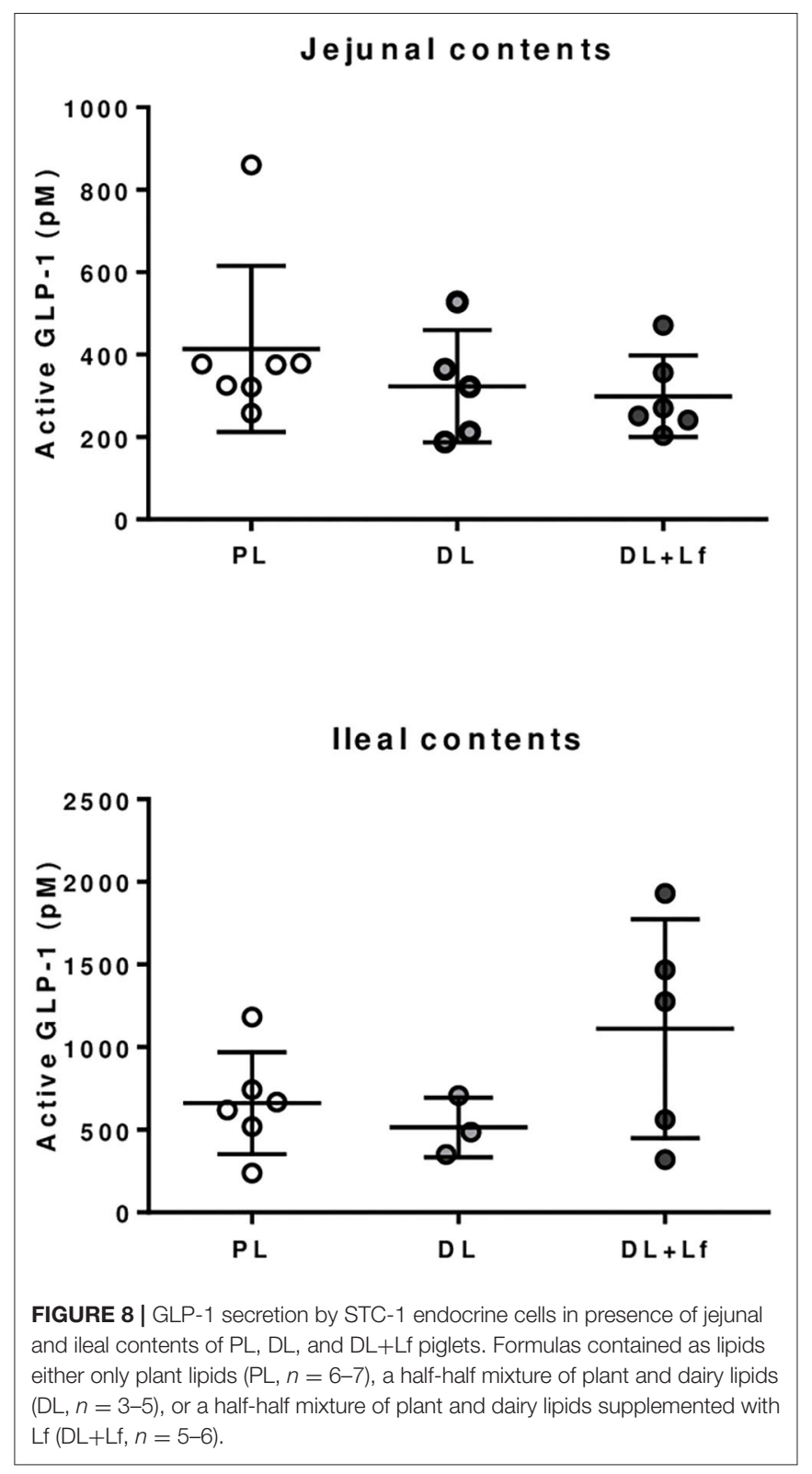

savings" was observed in piglets supplemented with prebiotic short chain fructooligosaccharides (scFOS), suggesting a lower insulin demand and potentially a better insulin sensitivity of peripheral tissues to insulin (35) even if the postprandial insulin and the insulin/glucose ratio did not display a significant decrease in DL+Lf. As supplementation of both probiotic Lf and prebiotic scFOS is susceptible to modify intestinal microbiota, this "pancreatic savings" could be related to intestinal microbiota modification between groups. Intestinal GLP-1 secreting function (i.e., number and percentage of GLP1 secreting enteroendocrine L-cells) and postprandial GLP-1 concentration were not different between groups. This was in agreement with the in vitro STC-1 results demonstrating no difference in the GLP-1 secretion stimulating capacity of 
intestinal contents, despite differences in their peptide and lipid compositions. In contrast, we reported a long-term promoting effect of Lf on GLP-1 secreting function in the adult minipigs under a hyperenergetic-diet challenge, suggesting that a deleterious nutritional environment was necessary to reveal the metabolic programming (11). Finally, a trophic effect of probiotic Lf was observed on duodenum and jejunum weights, as well as on small intestine length. This is coherent with a recent study that also observed an intestinal trophic effect of this specific strain (36). Mechanisms responsible for the modulation of intestinal growth by Lf remain unknown, but could involve, for instance, a modulation of microbiota composition (11).

The use of piglets as models for infants was a strength of our study, the piglet having many common features with infant regarding nutritional physiology and functional gut maturation (7). Furthermore, regarding lipid digestion, as for breast milk, palmitic acid in sow milk is mainly on the sn-2 position $70 \%$, (37), and as for humans, pig pancreatic lipase mainly hydrolyzes fatty acids on the sn-1,3 positions, and palmitic acid is wellabsorbed through the gut epithelium as a monoacyl glycerol (38). Therefore, piglets are very good models for infants in this regard. However, our study also displayed some limitations. For instance, it would have been optimal to have a fourth group of animals receiving the $\mathrm{PL}$ formula plus probiotic. However, because of economical and ethical constraints, we had to limit the number of experimental piglets and could consider only three groups. In particular, we selected the three groups $\mathrm{PL}, \mathrm{DL}$, and DL+Lf to achieve our goal of investigating the role of re-introduction of dairy lipids in infant formula on its digestion and on the intestinal physiology, and its eventual synergy with probiotic Lf. Also, a basal (fasting) point would be needed to evaluate the amplitude of the postprandial $(90 \mathrm{~min})$ response and compare it between formulas. However, as infants, piglets eat every $2 \mathrm{~h}$ during the suckling period, so there is technically no fasting period that could have been taken as a reference. The timepoint $90 \mathrm{~min}$ was therefore a good compromise for assessing the digestion process in suckled minipigs (16).

In conclusion, our data provide interesting knowledge about how infant formulas with different lipid nature (plant vs. dairy) and probiotic content may be differently digested, with consequences on gut physiology. More precisely, the addition of dairy lipids in infant formula modulated the digestion of lipids, whereas the addition of Lf increased proteolysis, had an intestinal trophic effect, increased the number of goblet cells, and induced a "pancreas savings" effect. Our results corroborate the synergistic properties of MFGMs and probiotics reported on mucosal Band T-cell proliferation and mucosal IgA-secreting cells (39). The adhesion of lactic acid bacteria strains to MFGM, previously demonstrated for Lactobacillus reuteri, may participate in the greater impact of the combination of dairy lipids and Lf compared to individual ingredients (40). All these effects had potential nutritional relevance due to bioactive peptides and AMPs and lipolysis products, and displayed beneficial, although moderate, effects on non-specific host defenses and intestinal size, as well as metabolism. Overall, we did not notice any effect of dairy lipids with or without Lf on piglet growth. This was also the case in infants receiving formulas supplemented with either MFGM or another probiotic strain (Lactobacillus paracasei ssp. paracasei strain) (41).

\section{DATA AVAILABILITY STATEMENT}

The original contributions presented in the study are included in the article/Supplementary Material, further inquiries can be directed to the corresponding author/s.

\section{ETHICS STATEMENT}

The animal study was reviewed and approved by The ethics committees of CREEA (Rennes Committee of Ethics in Animal Experimentation) and of the France's Ministry of Higher Education and Research approved the entire protocol (authorization \#2016011111546978).

\section{AUTHOR CONTRIBUTIONS}

IL, SB, DD, PL, and CB conceived the project and ML, IL, $\mathrm{SB}, \mathrm{DD}, \mathrm{PL}$, and $\mathrm{CB}$ designed the experiment. IC, PL, and $\mathrm{CB}$ provided the infant formulas. $\mathrm{ML}, \mathrm{OM}, \mathrm{AC}, \mathrm{IN}, \mathrm{VB}-\mathrm{B}$, $\mathrm{BC}, \mathrm{AD}, \mathrm{IL}$, and $\mathrm{SB}$ performed analysis. $\mathrm{ML}, \mathrm{OM}, \mathrm{BC}, \mathrm{AD}$, $\mathrm{DD}, \mathrm{SB}$, and IL analyzed the data. ML, AD, SB, and IL wrote the draft manuscript. All authors reviewed and approved the final manuscript.

\section{FUNDING}

The present work received funding from Lactalis Recherche et Développement (Retiers, France) and from the Association Nationale de la Recherche et de la Technologie (ANRT) (Grant CIFRE No. 2014/0580).

\section{ACKNOWLEDGMENTS}

The authors acknowledge all the staff of Rennes porcine experimental facilities (UE3P, especially Francis Le Gouevec, Julien Georges and Mickaël Genissel) for their professionalism, help, expert assistance and animal care and feeding. The authors thank Laure France for infant formulas manufacturing, Claire Bourlieu and Florian Kroell for their help in data analysis, and Rezak Mendil for its technical support during the in vitro GLP-1 secretion study.

\section{SUPPLEMENTARY MATERIAL}

The Supplementary Material for this article can be found online at: https://www.frontiersin.org/articles/10.3389/fnut.2021. 615248/full\#supplementary-material 


\section{REFERENCES}

1. Bourlieu C, Menard O, Bouzerzour K, Mandalari G, Macierzanka A, Mackie AR, et al. Specificity of infant digestive conditions: some clues for developing relevant in vitro models. Crit Rev Food Sci Nutr. (2014) 54:142757. doi: 10.1080/10408398.2011.640757

2. Victora CG, Bahl R, Barros AJ, Franca GV, Horton S, Krasevec J, et al. Breastfeeding in the 21st century: epidemiology, mechanisms, and lifelong effect. Lancet. (2016) 387:475-90. doi: 10.1016/S0140-6736(15)0 1024-7

3. Bourlieu C, Deglaire A, de Oliveira SC, Ménard O, Le Gouar Y, Carrière F, et al. Towards infant formula biomimetic of human milk structure and digestive behaviour. OCL. (2017) 24:D206. doi: 10.1051/ocl/2017010

4. Miles EA, Calder PC. The influence of the position of palmitate in infant formula triacylglycerols on health outcomes. Nutrition Res. (2017) 44:18. doi: 10.1016/j.nutres.2017.05.009

5. Delplanque B, Gibson R, Koletzko B, Lapillonne A, Strandvik B. Lipid quality in infant nutrition: current knowledge and future opportunities. $J$ Pediatr Gastroenterol Nutr. (2015) 61:8-17. doi: 10.1097/MPG.00000000000 00818

6. Innis SM. Dietary triacylglycerol structure and its role in infant nutrition. $A d v$ Nutr. (2011) 2:275-83. doi: 10.3945/an.111.000448

7. Roura E, Koopmans SJ, Lalles JP, Le Huerou-Luron I, de Jager N, Schuurman $\mathrm{T}$, et al. Critical review evaluating the pig as a model for human nutritional physiology. Nutr Res Rev. (2016) 29:60-90. doi: 10.1017/S09544224160 00020

8. Le Huerou-Luron I, Bouzerzour K, Ferret-Bernard S, Menard O, Le Normand L, Perrier C, et al. A mixture of milk and vegetable lipids in infant formula changes gut digestion, mucosal immunity and microbiota composition in neonatal piglets. Eur J Nutr. (2016) 57, 463-76. doi: 10.1007/s00394-016-1329-3

9. Martin R, Olivares M, Marin ML, Fernandez L, Xaus J, Rodriguez JM. Probiotic potential of 3 Lactobacilli strains isolated from breast milk. J Human Lactat. (2005) 21:8-17. doi: 10.1177/0890334404272393

10. Vanhaecke T. Modulation nutritionnelle du développement postnatal des fonctions neuro-digestives. Ph.D. thesis. Univ. Nantes, France (2016).

11. Lemaire M, Dou S, Cahu A, Formal M, Le Normand L, Romé V, et al. Addition of dairy lipids and probiotic Lactobacillus fermentum in infant formula programs gut microbiota and entero-insular axis in adult minipigs. Sci Rep. (2018) 8:11656. doi: 10.1038/s41598-018-29971-w

12. Adriaenssens AE, Reimann F, Gribble FM. Distribution and stimulus secretion coupling of enteroendocrine cells along the intestinal tract. Compr Physiol. (2018) 8:1603-38. doi: 10.1002/cphy.c170047

13. Caron J, Domenger D, Dhulster P, Ravallec R, Cudennec B. Protein digestion-derived peptides and the peripheral regulation of food intake. Front Endocrinol. (2017) 8:85. doi: 10.3389/fendo.2017.00085

14. Morise A, Seve B, Mace K, Magliola C, Le Huerou-luron I, Louveau I. Impact of intrauterine growth retardation and early protein intake on growth, adipose tissue, and the insulin-like growth factor system in piglets. Pediatr Res. (2009) 65:45-50. doi: 10.1203/PDR.0b013e318189b0b4

15. Zheng H, Jiménez-Flores R, Everett DW. Bovine milk fat globule membrane proteins are affected by centrifugal washing processes. J Agric Food Chem. (2013) 61:8403-11. doi: 10.1021/jf402591f

16. Bouzerzour K, Morgan F, Cuinet I, Bonhomme C, Jardin J, Le HuerouLuron I, et al. In vivo digestion of infant formula in piglets: protein digestion kinetics and release of bioactive peptides. Br J Nutr. (2012) 108:210514. doi: 10.1017/S000711451200027X

17. Bourlieu C, Ménard O, De La Chevasnerie A, Sams L, Rousseau F, Madec M$\mathrm{N}$, et al. The structure of infant formulas impacts their lipolysis, proteolysis and disintegration during in vitro gastric digestion. Food Chem. (2015) 182:224-35. doi: 10.1016/j.foodchem.2015.03.001

18. Darrouzet-Nardi A, Ladd MP, Weintraub MN. Fluorescent microplate analysis of amino acids and other primary amines in soils. Soil Biol Biochem. (2013) 57:78-82. doi: 10.1016/j.soilbio.2012.07.017

19. Deglaire A, De Oliveira SC, Jardin J, Briard-Bion V, Emily M, Menard O, et al. Impact of human milk pasteurization on the kinetics of peptide release during in vitro dynamic term newborn digestion. Electrophoresis. (2016) 37:1839-50. doi: 10.1002/elps.201500573
20. Minkiewicz P, Dziuba J, Iwaniak A, Dziuba M, Darewicz M. BIOPEP database and other programs for processing bioactive peptide sequences. J AOAC Int. (2008) 91:965-80. doi: 10.1093/jaoac/91.4.965

21. Waghu FH, Barai RS, Gurung P, Idicula-Thomas S. CAMPR3: a database on sequences, structures and signatures of antimicrobial peptides. Nucleic Acids Res. (2016) 44:D1094-7. doi: 10.1093/nar/gkv1051

22. Gabere MN, Noble WS. Empirical comparison of web-based antimicrobial peptide prediction tools. Bioinformatics. (2017) 33:1921-9. doi: 10.1093/bioinformatics/btx081

23. Oliveira S, Deglaire A, Ménard O, Bellanger A, Rousseau F, Henry G, et al. Holder pasteurization impacts the proteolysis, lipolysis and disintegration of human milk under in vitro dynamic term newborn digestion. Food Res Int. (2016) 88:263-75. doi: 10.1016/j.foodres.2015.11.022

24. Jong CD, Badings HT. Determination of free fatty acids in milk and cheese procedures for extraction, clean up, and capillary gas chromatographic analysis. J High Resolut Chromatogr. (1990) 13:948. doi: 10.1002/jhrc.1240130204

25. Menard O, Bourlieu C, De Oliveira SC, Dellarosa N, Laghi L, Carriere $\mathrm{F}$, et al. A first step towards a consensus static in vitro model for simulating full-term infant digestion. Food Chem. (2018) 240:33845. doi: 10.1016/j.foodchem.2017.07.145

26. Le Bourgot C, Ferret-Bernard S, Le Normand L, Savary G, MenendezAparicio E, Blat S, et al. Maternal short-chain fructooligosaccharide supplementation influences intestinal immune system maturation in piglets. PLoS ONE. (2014) 9:e107508. doi: 10.1371/journal.pone.01 07508

27. R Core Team. R: A Language and Environment for Statistical Computing. $\mathrm{R}$ Foundation for Statistical Computing, Vienna, Austria. (2014) URL http:// www.R-project.org/

28. Cardenas N, Laino JE, Delgado S, Jimenez E, Juarez del Valle M, Savoy de Giori G, et al. Relationships between the genome and some phenotypical properties of Lactobacillus fermentum CECT 5716, a probiotic strain isolated from human milk. Appl Microbiol Biotechnol. (2015) 99:434353. doi: 10.1007/s00253-015-6429-0

29. Olivares M, Schüppel V, Hassan AM, Beaumont M, Neyrinck AM, Bindels $\mathrm{LB}$, et al. The potential role of the dipeptidyl peptidase-4-like activity from the gut microbiota on the host health. Front Microbiol. (2018) 9:1900. doi: 10.3389/fmicb.2018.01900

30. Olivares M, Díaz-Ropero MP, Martín R, Rodríguez JM, Xaus J. Antimicrobial potential of four Lactobacillus strains isolated from breast milk. J Appl Microbiol. (2006) 101:72-9. doi: 10.1111/j.1365-2672.2006.02981.x

31. Daniel H, Vohwinkel M, Rehner G. Effect of casein and betacasomorphins on gastrointestinal motility in rats. J Nutr. (1990) 120:252-7. doi: 10.1093/jn/120.3.252

32. Patten GS, Head RJ, Abeywardena MY, McMurchie EJ. An apparatus to assay opioid activity in the infused lumen of the intact isolated guinea pig ileum. J Pharmacol Toxicol Methods. (2001) 45:39-46. doi: 10.1016/S.1056-8719(01)00116-2

33. Nejrup RG, Bahl MI, Vigsnaes LK, Heerup C, Licht TR, Hellgren LI. Lipid hydrolysis products affect the composition of infant gut microbial communities in vitro. Br J Nutr. (2015) 114:63-74. doi: 10.1017/S0007114515000811

34. Neu J, Walker WR, Engelhardt EL, Wu-Wang CY, Roa MB, Thomas MR, et al. Alterations in piglet small intestine after cholesterol deprivation. Pediatr Res. (1987) 22:330-4. doi: 10.1203/00006450-198709000-00018

35. Le Bourgot C, Ferret-Bernard S, Apper E, Taminiau B, Cahu A, Le Normand L, et al. Perinatal short-chain fructooligosaccharides program intestinal microbiota and improve enteroinsular axis function and inflammatory status in high-fat diet-fed adult pigs. Faseb J. (2019) 33:301-13. doi: 10.1096/fj.201800108R

36. Vanhaecke T, Aubert P, Grohard PA, Durand T, Hulin P, Paul-Gilloteaux $\mathrm{P}$, et al. L. fermentum CECT 5716 prevents stress-induced intestinal barrier dysfunction in newborn rats. Neurogastroenterol Motil. (2017) 29:8. doi: 10.1111/nmo.13069

37. Lv Y, Zhang S, Guan W, Chen F, Zhang Y, Chen J, et al. Metabolic transition of milk triacylglycerol synthesis in response to varying levels of palmitate in porcine mammary epithelial cells. Genes Nutr. (2018) 13:18. doi: 10.1186/s12263-018-0606-6 
38. Innis SM, Dyer R, Quinlan P, Diersen-Schade D. Palmitic acid is absorbed as sn-2 monopalmitin from milk and formula with rearranged triacylglycerols and results in increased plasma triglyceride sn-2 and cholesteryl ester palmitate in piglets. J Nutr. (1995) 125:73-81.

39. Favre L, Bosco N, Roggero IS, Corthésy B, Benyacoub J. Combination of milk fat globule membranes and probiotics to potentiate neonatal immune maturation and early life protection. Pediatric Res. (2011) 70:4399. doi: 10.1038/pr.2011.664

40. Brisson G, Payken HF, Sharpe JP, Jiménez-Flores R. Characterization of Lactobacillus reuteri Interaction with milk fat globule membrane components in dairy products. J Agricult Food Chem. (2010) 58:56129. doi: 10.1021/jf904381s

41. Li X, Peng Y, Li Z, Christensen B, Heckmann AB, Stenlund H, et al. Feeding infants formula with probiotics or milk fat globule membrane: a double-blind, randomized controlled trial. Front Pediatr. (2019) 7:347. doi: $10.3389 /$ fped.2019.00347
Conflict of Interest: IC, PL, and CB are employees of Lactalis. ML received a grant from Lactalis Recherche et Développement (Retiers, France) and from the Association Nationale de la Recherche et de la Technologie (ANRT) (Grant CIFRE No. 2014/0580).

The remaining authors declare that the research was conducted in the absence of any commercial or financial relationships that could be construed as a potential conflict of interest.

Copyright (C) 2021 Lemaire, Ménard, Cahu, Nogret, Briard-Bion, Cudennec, Cuinet, Le Ruyet, Baudry, Dupont, Blat, Deglaire and Le Huërou-Luron. This is an openaccess article distributed under the terms of the Creative Commons Attribution License (CC BY). The use, distribution or reproduction in other forums is permitted, provided the original author(s) and the copyright owner(s) are credited and that the original publication in this journal is cited, in accordance with accepted academic practice. No use, distribution or reproduction is permitted which does not comply with these terms. 